\title{
Rational Design of Amyloid-Like Fibrillary Structures for Tailoring Food Protein Techno-Functionality and Their Potential Health Implications
}

Koen J.A. Jansens (iD , * Ine Rombouts, Charlotte Grootaert, Kristof Brijs, John Van Camp, Paul Van der Meeren, Frederic Rousseau, Joost Schymkowitz, and Jan A. Delcour

\begin{abstract}
To control and enhance protein functionality is a major challenge for food scientists. In this context, research on food protein fibril formation, especially amyloid fibril formation, holds much promise. We here first provide a concise overview of conditions, which affect amyloid formation in food proteins. Particular attention is directed towards amyloid core regions because these sequences promote ordered aggregation. Better understanding of this process will be key to tailor the fibril formation process. Especially seeding, that is, adding preformed protein fibrils to protein solutions to accelerate fibril formation holds promise to tailor aggregation and fibril techno-functionality. Some studies have already indicated that food protein fibrillation indeed improves their techno-functionality. However, much more research is necessary to establish whether protein fibrils are useful in complex food systems and whether and to what extent they resist food processing unit operations. In this review the effect of amyloid formation on gelation, interfacial properties, foaming, and emulsification is discussed. Despite their prevalent role as functional structures, amyloids also receive a lot of attention due to their association with protein deposition diseases, prompting us to thoroughly investigate the potential health impact of amyloid-like aggregates in food. A literature review on the effect of the different stages of the human digestive process on amyloid toxicity leads us to conclude that food-derived amyloid fibrils (even those with potential pathogenic properties) very likely have minimal impact on human health. Nevertheless, prior to wide-spread application of the technology, it is highly advisable to further verify the lack of toxicity of food-derived amyloid fibrils.
\end{abstract}

Keywords: amyloid, core region, nutritional properties, seeding, techno-functional properties

\section{Introduction}

The behavior and functionality of proteins in food systems are largely determined by their conformation (Foegeding \& Davis, 2011; Nicolai \& Durand, 2013). Fibrillar protein structures are typically good thickening and gelling agents (Akkermans et al., 2007; Loveday, Rao, Creamer, \& Singh, 2009). Food proteins can form gels in various ways. Fine-stranded and particulate gels are

CRF3-2018-0145 Submitted 7/29/2018, Accepted 10/3/2018. Authors Jansens, Rombouts, Brijs, and Delcour are with Laboratory of Food Chemistry and Biochemistry and Leuven Food Science and Nutrition Research Centre (LFoRCe), KU Leuven, Kasteelpark Arenberg 20, B-3001 Leuven, Belgium. Grootaert and Van Camp are with Laboratory of Food Chemistry and Human Nutrition, Ghent Univ., Coupure Links 653, B-9000 Ghent, Belgium. Author Van der Meeren is with Particle and Interfacial Technology Group, Ghent Univ., Coupure Links 653, B- 9000 Ghent, Belgium. Authors Rousseau and Schymkowitz are with Switch Laboratory, VIB, B3000 Leuven, Belgium. Authors Rousseau and Schymkowitz are also with Dept. of Cellular and Molecular Medicine, KU Leuven, B-3000 Leuven, Belgium. Direct inquiries to author Jansens (E-mail: Koen.Jansens@motd.be).

*Author Jansens is currently with Nutrex NV, Achterstenhoek 5, 2275 Lille, Belgium respectively dominated by fibrous (linear) and amorphous (nonlinear) protein aggregates (Foegeding \& Davis, 2011; Nicolai \& Durand, 2013). The more extensive protein unfolding in finestranded gels allows for closer alignment of polypeptide chains and much stronger hydrogen bonds than in particulate gels (Lefevre \& Subirade, 2000). Overall, these differences in protein conformation and protein-protein interactions are responsible for specific macroscopic gel properties. Fine-stranded gel networks are often (semi-)transparent, elastic, of low critical gel concentration, and have high water binding capacity (Lefevre \& Subirade, 2000). Fibrillar protein structures are often also effective as foam stabilizers and emulsifiers (Fameau \& Salonen, 2014; Kroes-Nijboer, Venema, \& van der Linden, 2012). Furthermore, they can display exceptional interfacial properties as nicely demonstrated for fibrils from whey proteins (Oboroceanu, Wang, Magner, \& Auty, 2014), ovalbumin, and hen egg lysozyme (Humblet-Hua, van der Linden, \& Sagis, 2013).

A specific kind of fibrillar protein structure is the amyloid fibril (AF). It was first described in 1854 by Rudolph Virchow (Sipe \& Cohen, 2000). Based on an iodine staining experiment, he falsely 


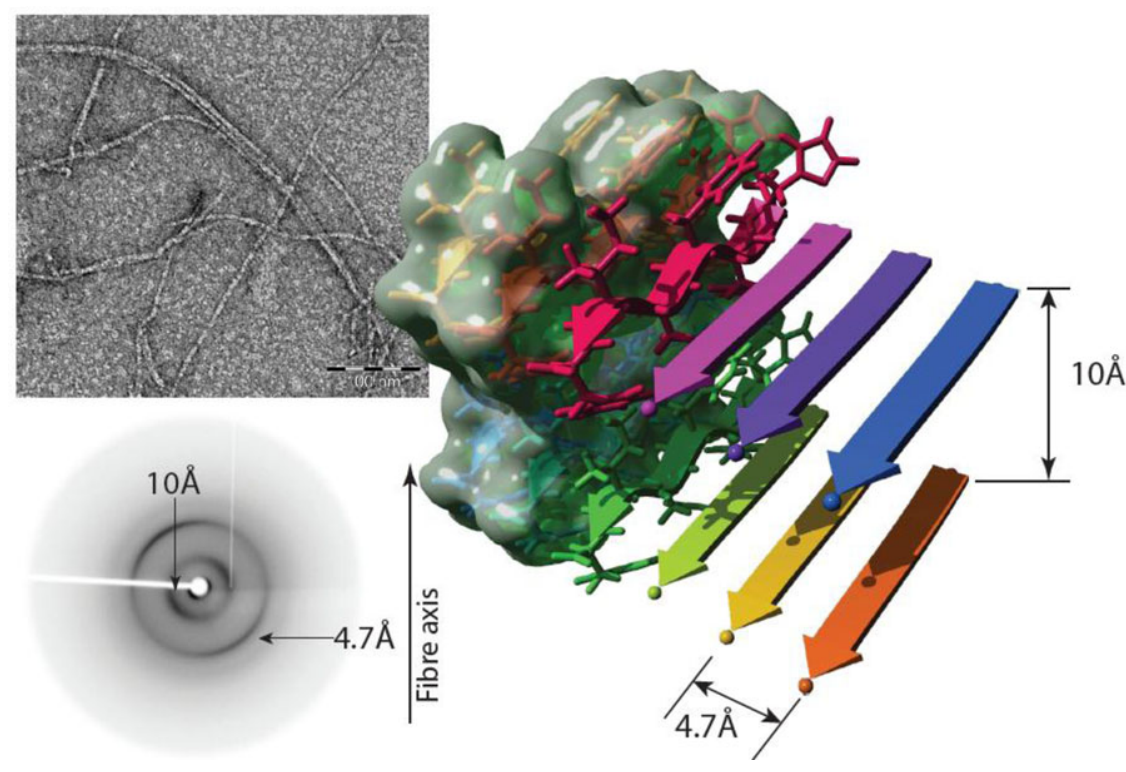

Figure 1-Transmission electron microscopy image and X-ray diffraction (XRD) pattern of the peptide vascin [reproduced from Gallardo et al. (2016), with permission]. The fibril structure is that of the peptide HYFNIF, that is, a fragment of the human Bloom syndrome protein. The peptide was identified by Maurer-Stroh et al. (2010), its structure resolved by Morris et al. (2013). The image was created with Yasara (Krieger, Koraimann, \& Vriend, 2002).

identified particular protein deposits in human tissue as starch (Latin: amylum; Aterman, 1976). Under some conditions, partially unfolded proteins self-assemble into highly ordered nanofibers with a $\beta$-sheet core consisting of identical sequence segments with tight side chain packing resulting in $\beta$-strands stacked perpendicularly along the axis of the fibril and stabilized by intermolecular hydrogen bonds, often referred to as a cross- $\beta$ structure (Figure 1; Chiti \& Dobson, 2006; Harrison, Sharpe, Singh, \& Fairlie, 2007; Knowles et al., 2007). This leads to a typical fiber X-ray diffraction (XRD) pattern with reflections at $4.7 \AA$ and around $10 \AA$ (Sunde et al., 1997). In addition, the amyloid $\beta$-sheet structures give green birefringence under cross-polarized light when stained with Congo red and they fluoresce after binding to thioflavin T (Harrison et al., 2007). Amyloid polymeric fibrils can have a diameter of approximately 3 to $15 \mathrm{~nm}$ and a length of 0.1 to $10 \mu \mathrm{m}$. They have a rigid structure with superior mechanical strength (Gebbink, Claessen, Bouma, Dijkhuizen, \& Wosten, 2005).

Although amyloids are firmly associated with misfolded and partially folded proteins in the context of pathology and diseases (such as Alzheimer's, Huntington, Parkinson, type II diabetes, and rheumatoid arthritis; Chiti \& Dobson, 2006; Harrison et al., 2007; Pham, Kwan, \& Sunde, 2014), the characteristic fiber XRD pattern has first (about 80 years earlier) been observed in proteins from hen egg white (Astbury, Dickinson, \& Bailey, 1935). In addition, more recent work has identified multiple cases of amyloid fibers in bacteria, fungi, insects, invertebrates, and humans that serve several important functional roles (Barlow et al., 2010; Fowler, Koulov, Balch, \& Kelly, 2007; Gebbink et al., 2005). Examples of such functional amyloids are those involved in biofilms formed by bacteria (for example, curli and chaplins proteins secreted by E.coli and Streptomycetes, respectively; Garcia-Sherman, Lundberg, Sobonya, Lipke, \& Klotz, 2015; Gebbink et al., 2005), fungal adherence (for example, hydrophobins; Garcia-Sherman et al., 2014), barnacle attachment to the marine surface (Nakano \& Kamino, 2015), and the formation of the amyloid coat of mammalian oocytes by the zona pellucida protein (Egge, Muthusubramanian, \& Cornwall, 2015). Another example is that the amyloid form of the human premelanosome protein protects melanocytes from melanin polymerization toxicity (Watt, van Niel, Raposo, \& Marks, 2013). Although much less data is available on amyloid-like aggregates from food proteins, a variety of such proteins including lysozyme (Hill, Robinson, Matthews, \& Muschol, 2009; Krebs et al., 2000; Mishra et al., 2007), $\beta$-lactoglobulin (Bromley, Krebs, \& Donald, 2005; Hamada et al., 2009; Loveday, Wang, Rao, Anema, \& Singh, 2012), ovalbumin (Lara, Gourdin-Bertin, Adamcik, Bolisetty, \& Mezzenga, 2012; Pearce, Mackintosh, \& Gerrard, 2007; Tanaka et al., 2011), soy glycinin (Akkermans et al., 2007; Tang \& Wang, 2010; Wang et al., 2011; US Patent No. PCT/US2012/059034, 2012) and wheat gluten (Athamneh \& Barone, 2009a; Mackintosh et al., 2009; Ridgley \& Barone, 2013; Ridgley, Claunch, \& Barone, 2012; Ridgley, Claunch, Lee, \& Barone, 2014; Ridgley, Ebanks, \& Barone, 2011) readily form fibrillar structures under specific experimental conditions, of which some are relevant in food processing.

Amyloid formation seems to be a generic property of all peptides (Mezzenga \& Fischer, 2013; Rambaran \& Serpell, 2008) and research on amyloid formation within a food context is increasing. World population and prosperity growth in developing countries have led to an exceptional rise in the demand for proteins. The food industry today faces the major challenge to enhance protein functionality, for example, for partially or fully replacing animal proteins which are by their own nature less sustainable than vegetable proteins but often have superior techno-functional quality. Although rational design of food protein fibrils holds promise for food structuring applications (Fameau \& Salonen, 2014; Lam \& Nickerson, 2013), more fundamental research is needed in this area. In addition, some food safety concerns have emerged as the link of amyloid structures to some human diseases is not understood. This review provides the state of the art on amyloid formation by food proteins. It thereby addresses the importance of 
core regions and discusses the potential of seeding and cross-seeding approaches. Furthermore, it throws light on the link between AF formation, techno-functional properties, and potential health impact. For more information on food protein aggregation in general as well as other types of food protein aggregation we refer to other reviews such as those written by Nicolai and Durand (2013) and Mezzenga and Fischer (2013).

\section{Amyloid Formation of Food Proteins}

AF formation can take place under a range of conditions (Krebs et al., 2000; Swaminathan, Ravi, Kumar, Kumar, \& Chandra, 2011). It is generally favored over disordered aggregation under conditions where aggregation is sufficiently slow to allow the specific structures to form. Typically, it starts with (partially) unfolded proteins (Adamcik \& Mezzenga, 2012) which under commonly used conditions are in equilibrium with the dissolved globular state (Figure 2). However, depending on, for example, temperature and $\mathrm{pH}$, the equilibrium can be displaced (Adamcik \& Mezzenga, 2012). The most frequently described conditions for forming fibrils from food proteins involve heating at moderate temperature under strongly acidic conditions (Moayedzadeh, Madadlou, \& Asl, 2015; Swaminathan et al., 2011). Under such conditions, some protein hydrolysis can take place which leads to both fibril-forming and non-fibril-forming peptides (KroesNijboer, Venema, Bouman, \& van der Linden, 2011). Hence, the formation of peptides by hydrolysis may precede their incorporation into fibrils. However, in such case, only part of the peptides formed are incorporated into fibrils.

Lysozyme fibril formation under acidic conditions has been described as a nucleation growth process (Meisl et al., 2016). First, lysozyme monomers during a lag phase aggregate into small oligomers of uniform size without a nucleation barrier (Hill et al., 2009). Such oligomers can be formed from (partially) unfolded protein (Figure 2) or from partially hydrolyzed protein (Adamcik \& Mezzenga, 2012). When a critical threshold concentration of oligomers is reached, they assemble into protofilaments. These then act as nucleating agents and rapid growth occurs by adding oligomers at their ends. Finally, the protofibrils self-assemble into much longer and stiffer mature fibrils (Hill et al., 2009). However, it is not always clear whether the same mechanism is involved when amyloid-like aggregates are formed under other conditions (Kalapothakis et al., 2015).

Whatever be the case, several factors affect fibril formation. These include temperature (Ow \& Dunstan, 2013; Pearce et al., 2007), pH (Arnaudov \& de Vries, 2005; Jansens, Brijs, Stetefeld, Delcour, \& Scanlon, 2017), ionic strength (Aso, Shiraki, \& Takagi, 2007; Wang, Chen, \& Hung, 2006), and agitation (Lieu, Wu, Wang, \& Wu, 2007; Ow \& Dunstan, 2013; Sasahara, Yagi, Naiki, \& Goto, 2007). Fibril formation is enhanced at higher temperatures (Pearce et al., 2007). However, at too high temperature, it may also be decreased due to competition with amorphous aggregation (Arnaudov \& de Vries, 2005; Ow \& Dunstan, 2013). Proteins such as lysozyme and ovalbumin form AFs upon incubation at moderate temperature and low $\mathrm{pH}$. At such $\mathrm{pH}$, partial hydrolysis may take place and give rise to both amyloid-promoting and non-amyloidogenic peptides. However, some proteins (for example, ovalbumin, bovine serum albumin [BSA]) also form amyloidlike aggregates at neutral pH (Arnaudov \& de Vries, 2005; Pearce et al., 2007; Tanaka et al., 2011). Fibril formation further strongly depends on the ionic strength of the medium, and, hence, on electrostatic interactions (Hill, Miti, Richmond, \& Muschol, 2011; Raccosta, Martorana, \& Manno, 2012). Both the lag time for fibril formation under acidic conditions and the critical protein concentration below which no significant fibril formation occurs decrease when salt concentration increases (Arnaudov \& de Vries, 2006; Hill et al., 2011; Loveday, Su, Rao, Anema, \& Singh, 2011). Salts also affect fibril morphology. At high ionic strength short, curvy, and/or highly branched fibrils are formed whereas those formed at low ionic strength are long and straight (Arnaudov \& de Vries, 2006; Kavanagh, Clark, \& Ross-Murphy, 2000; Pouzot, Nicolai, Visschers, \& Weijers, 2005; Veerman, Ruis, Sagis, \& van der Linden, 2002). Not just the charge itself, but also its distribution over the protein molecule can play a crucial role in determining the fibril properties (Weijers et al., 2008). More extensive discussion on the effect of charge on the structure of AF can amongst others be found in Adamcik and Mezzenga (2011) and Assenza, Adamcik, Mezzenga, and De Los Rios (2014). Agitation can enhance fibril formation (Akkermans, van der Goot, Venema, van der Linden, \& Boom, 2008a; Lieu et al., 2007), and fibril morphology can be affected by the flow conditions (Humblet-Hua, Sagis, \& van der Linden, 2008). The reduction of disulfide bridges can have a strong impact on amyloid formation, the extent of which depends on the protein involved. The presence of a disulfide reducing agent during ovalbumin amyloid formation results in larger particles with an increased thioflavin $\mathrm{T}$ fluorescence and surface hydrophobicity and altered volumetric properties (Jansens, Brijs, Delcour, \& Scanlon, 2016). Also, whereas semi-flexible fibrils are formed upon heating intact ovalbumin at neutral $\mathrm{pH}$, long straight fibrils are formed from disulfide reduced ovalbumin (Tanaka et al., 2011). In contrast, fibril formation of lysozyme under acidic conditions is (partially) inhibited by the disulfide reducing agents cysteine (Takai et al., 2014; Wang, Liu, Wu, \& Lai, 2009) and glutathione (Wang, Chou, Liu, \& Wu, 2009). Some proteins such as ovalbumin and lysozyme together can form amyloid-like structures (Yasushi Sugimoto et al., 2011b). High sugar contents may interfere with fibril formation. Upon heating of protein-sugar mixtures either in the dry or wet state, protein glycation can occur. The covalent bonding of sugar molecules strongly inhibits self-assembly of $\beta$-lactoglobulin in the growth phase, whereby lactosylation produces a much stronger effect than glucosylation. The large polar residues on glycated fribrillogenic peptides may inhibit fibril assembly by imposing steric restrictions and disrupting hydrophobic interactions (Dave, Loveday, Anema, Jameson, \& Singh, 2014).

Water plays multifarious roles. In the case of proteins with predominantly hydrophobic sequences it accelerates fibril formation. In contrast, water-stabilized metastable intermediates dramatically slow down fibril growth in hydrophilic sequences (Thirumalai, Reddy, \& Straub, 2012). Freezing of some proteins can accelerate the formation of fibrils, as demonstrated for the $\alpha$-helical type I antifreeze protein of the winter flounder (Graether, Slupsky, \& Sykes, 2003). More in particular, the extensive ice-water interfaces that form during slow freezing promote fibril formation (Sharp, Forrest, \& Jones, 2002).

\section{(Food) Protein Amyloid Core Regions and Their Importance for Tailoring Aggregation}

Amyloid-forming proteins contain sequences that promote ordered aggregation (Figure 3; Chiti et al., 2002; de la Paz \& Serrano, 2004). Such sequences combine a high $\beta$-sheet propensity, low net charge, and a high hydrophobicity (De Baets, Schymkowitz, \& Rousseau, 2014). In functional and disease-related amyloids alike, these regions are typically 5 to 15 amino acids in length and occur roughly once every 100 amino acids (Das et al., 2014; 


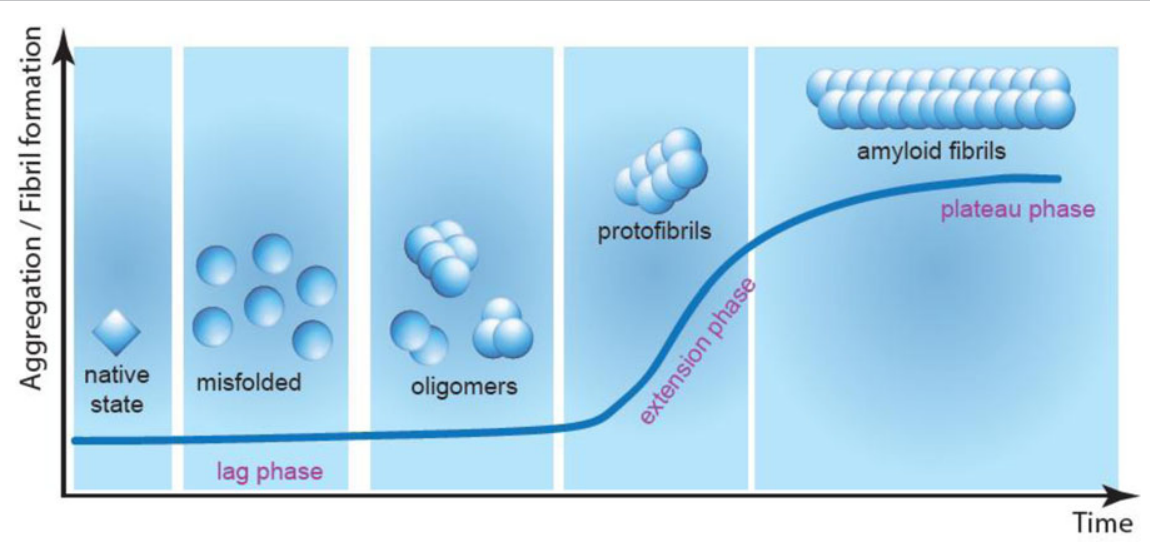

Figure 2-Scheme representing the sequence of events in the conversion of native proteins into amyloid fibrils (AFs) starting from the native proteins.

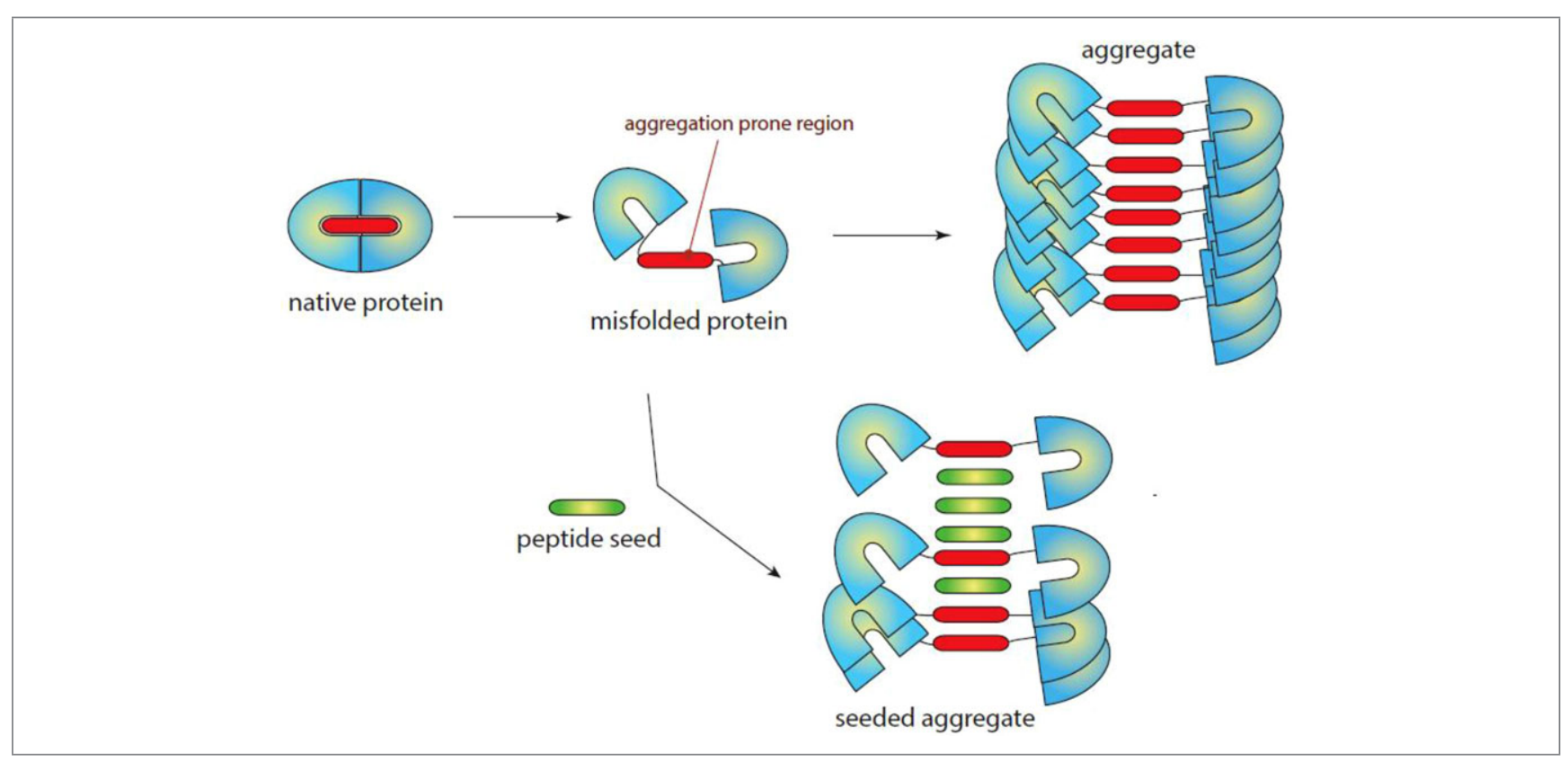

Figure 3-Scheme representing the formation of aggregates following the conversion of native protein into a misfolded variant which exposes an aggregate prone region. In the presence of peptide seeds, these lead to seeded aggregates in which the seeds interact with each other or with aggregate prone regions of the protein.

Rousseau, Serrano, \& Schymkowitz, 2006). Over the past decade, a host of prediction algorithms (for example, TANGO, AGGRESCAN, PASTA, WALTZ; Conchillo-Sole et al., 2007; FernandezEscamilla, Rousseau, Schymkowitz, \& Serrano, 2004; MaurerStroh et al., 2010; Trovato, Seno, \& Tosatto, 2007) have been developed to characterize the intrinsic aggregation propensity of polypeptides and thus to identify the regions of a protein sequence with high $\beta$-aggregation propensity. These algorithms can be divided into three main categories:

(1) Algorithms like TANGO (Fernandez-Escamilla et al., 2004), ZYGGREGATOR (Tartaglia \& Vendruscolo, 2008), or AGGRESCAN (Conchillo-Sole et al., 2007) are based on calculating average physico-chemical properties of sequence segments and identifying those with a high propensity to aggregate. This is done by evaluating properties like $\beta$-sheet propensity, net charge, and hydrophobicity or combinations thereof.
(2) Algorithms like WALTZ (Maurer-Stroh et al., 2010) and 3DPROFILE (Goldschmidt, Teng, Riek, \& Eisenberg, 2010; Thompson et al., 2006) are more strictly based on the structure of the AFs and are hence more specific towards highly ordered AFs, in contrast to the first set of methods, which tend to be more general.

(3) In addition to these first principle based methods, a range of machine learning algorithms such as AMYL-PRED (Frousios, Iconomidou, Karletidi, \& Hamodrakas, 2009) have also been proposed. They either make direct use of the primary sequence or of the output of primary methods from the previous categories to reach a prediction.

In general, there is a relatively large agreement between methods, although specificity and sensitivity differ depending on the type of sequences used to evaluate (Hamodrakas, 2011).

The core regions have been studied only for a few food protein amyloids (Table 1). Starting from the algorithms mentioned 
Tailoring food protein functionality...

Table 1-Sequences of food proteins of relevance for amyloid aggregation. The sequence were identified analytically and/or using prediction algorithms.

\begin{tabular}{lll}
\hline Protein & Sequence & Reference \\
\hline$\beta$-Lactoglobulin & LIVTQTMKGLD, & Akkermans et al. (2008) \\
$\beta$-Lactoglobulin & IQKVAGTWYSLAMAASDISLLD & Hamada and Dobson (2002) \\
& DIQKVAGTWY, KYLLFCMENS, & \\
Lysozyme & yHIRLSFN & Krebs et al. (2000), Frare et al. (2004) \\
Lysozyme & GSTDYGILQINSRWWC & Sugimoto et al. (2011a) \\
Lysozyme & GILQINSRW & Lara et al. (2014) \\
Ovalbumin & ILQINS & Lara et al. (2012) \\
Ovalbumin & LAMVYL, MVLVNAIVFK & Kawachi et al. (2013) \\
Ovalbumin & FLFCIK & SQTAMVLVNAIVFKGLWEKAFK \\
\hline
\end{tabular}

above, Tanaka et al. (2011) identified the sequences LAMVYL, MVLVNAIVFK, and FLFCIK in ovalbumin as genuine core regions for fibril formation. These sequences can also form AFs on their own when heated at neutral $\mathrm{pH}$. Due to solubility issues it could not be established whether this is also the case for the longer peptide IAIMSALAMVYL. SQTAMVLVNAIVFKGLWEKAFK, which contains the above mentioned sequence MVLVNAIVFK has also been identified using mass spectrometry (MS) as being part of fibrils obtained when heating ovalbumin under acidic conditions (Lara et al., 2012). The $N$-terminal peptide $\mathrm{pN}_{1-22}$ of ovalbumin (GSIGAASMEFCFDVFKELKVHH) can form amyloidlike aggregates on its own during heating under acidic conditions (Kawachi, Kameyama, Handa, Takahashi, \& Tanaka, 2013).

Amyloids from hen egg white lysozyme are the most in depth characterized food protein derived amyloids. Lysozyme fibrils obtained under acidic conditions consist of lysozyme fragments corresponding to residues 49 to 100/101 and 53 to 100/101 formed by partial hydrolysis of Asp-X peptide bonds (Frare, de Laureto, Zurdo, Dobson, \& Fontana, 2004; Mishra et al., 2007). The peptides containing residues 57 to 107 and 49 to 64 (GSTDYGILQINSRWWC) of lysozyme form AFs themselves respectively during incubation at $\mathrm{pH} 2.0$ and 4.0 (Frare et al., 2004; Krebs et al., 2000). That corresponding to residues 54 to 62 (GILQINSRW) aggregates into fibrils at $\mathrm{pH} 7.5$ and $25{ }^{\circ} \mathrm{C}$ (Sugimoto et al., 2011a). Although fibrils are also formed at neutral $\mathrm{pH}$, fibrils from this peptide are formed faster at $\mathrm{pH}$ 4.0. Tryptophan appears critical in this sequence since no fibrils are formed after deletion and substitution of this amino acid. Furthermore, the peptide also needs a certain length made up by hydrophobic amino acids for fibril formation to occur (Tokunaga, Sakakibara, Kamada, Watanabe, \& Sugimoto, 2013). Also the shorter fragment ILQINS (residues 55 to 60) can form fibrillar structures at $\mathrm{pH}$ 2.0. Upon prolonged incubation amyloid crystals are formed from this fragment (Lara et al., 2014). The tendency to form crystals is higher for related hexapeptides with certain mutations (TFQINS and IFQINS; Reynolds et al., 2017). Akkermans, Venema, van der Goot, Boom, and van der Linden (2008) prepared $\beta$-lactoglobulin fibrils under acidic conditions and separated fibrillar from non-fibrillar material using centrifugal filters. Next, they identified the peptides in both fractions. The peptide corresponding to residues 1 to 11 (LIVTQTMKGLD) was only present in fibrils whereas that corresponding to residues 12 to 33 (IQKVAGTWYSLAMAASDISLLD) was often present in the fibrillar material. Peptides corresponding to residues 64 to 96 were not detected in the fibrils. Clearly, not all peptides from $\beta$-lactoglobulin were incorporated into the fibrils (Akkermans et al., 2008). Amyloids from $\beta$-lactoglobulin can also be formed at neutral $\mathrm{pH}$ in the presence of urea. Under similar conditions the peptides corresponding to residues 11 to 20 (DIQKVAGTWY), 101 to 110
(KYLLFCMENS), and 146 to 152 (yHIRLSFN) formed fibrillar structures on their own (Hamada \& Dobson, 2002). Using the WALTZ and TANGO algorithms, Ghadami, Khodarahmi, Ghobadi, Ghasemi, and Pirmoradi (2011) reported that the amyloidogenic region of $\beta$-lactoglobulin is located between residues 80 and 110. As is evident from the above, other peptides can also form AFs. For gluten proteins, Ridgley et al. (2011) based on several prediction algorithms reported that the peptides corresponding to residues 3 to 22 and 162 to 207 of gliadin and that corresponding to 203 to 277 of low molecular weight glutenin subunits have a high propensity for $\beta$-sheet formation.

Although these research data clearly illustrate that food proteins possess the intrinsic ability to form cross- $\beta$ aggregates as well as AFs, the identification of amyloid core regions has often been biased towards confirming the role of aggregation prone sequences identified with existing prediction algorithms. This has the intrinsic risk of being a self-feeding cycle that disregards the role of other perhaps unexpected regions. In this context, it should be stressed that the algorithms developed to date are based on diseaserelated amyloids. For food protein-based amyloids they may very well require adaptation. Therefore, a more unbiased approach to identify aggregation determining regions in food-related proteins and in the most relevant food mixtures, such as mass spectrometric analysis of the peptides in fibrils is highly valuable. However, mass spectrometric analysis of amyloid cores is often challenging due the high stability of the amyloids which hampers their solubilization and tryptic digestion. Also, it is difficult to ionize highly hydrophobic peptides and thus to detect them in typical MS setups.

Understanding which sequences are part of the amyloid core region is of great importance, because soluble peptides containing these sequences can interfere with protein fibril formation (Kuroda, Maeda, Hanaoka, Miyamoto, \& Nakagawa, 2004; Tjernberg et al., 1996). Hence, approaches to selectively steer protein aggregation are possible with the correct peptide (mixture). For example, in the presence of IAIMSA, long straight fibrils were obtained upon heating ovalbumin at neutral $\mathrm{pH}$, whereas semi-flexible fibrils were formed without this peptide (Tanaka et al., 2011). Incubation of ovalbumin with the $N$-terminal region $\mathrm{pN}_{1-22}$ under acidic conditions resulted in straight fibrils that were distinct from the semi-flexible fibrils formed from intact ovalbumin incubated under the same conditions without such peptide (Kawachi et al., 2013). Interestingly, peptide-based seeding of protein aggregation also happens in living cells and organisms, as demonstrated in transgenic plants (Betti et al., 2016), in mammalian cells (Gallardo et al., 2016) and in bacteria (Bednarska et al., 2016).

Some peptides also more readily form fibrils than the intact protein containing the same peptide in its primary structure. The 
peptide corresponding to residues 49 to 64 of lysozyme readily forms fibrils when incubated at $37^{\circ} \mathrm{C}$ and $\mathrm{pH} 4.0$ for $24 \mathrm{hr}$, whereas full-length lysozyme requires heat at $\mathrm{pH} 2.0$ or addition of organic solvents followed by incubation for prolonged periods to form fibrils similar to those formed by the peptide within $24 \mathrm{hr}$. This can be attributed to the increased availability of core regions for aggregation as a result of hydrolysis (Krebs et al., 2000). Fibril formation is also possible from peptide mixtures obtained by enzymatic hydrolysis of proteins. Hydrolysis of $\beta$-lactoglobulin with AspN endoproteinase for $48 \mathrm{hr}$ at $\mathrm{pH} 8.0$ and $37^{\circ} \mathrm{C}$ yielded a peptide mixture which formed fibrils after $\mathrm{pH}$ adjustment to 2.0 and incubation at room temperature (Akkermans et al., 2008). Incubation of $\alpha$-lactalbumin with peptidase from Bacillus licheniformis at $\mathrm{pH} 7.5$ and $50{ }^{\circ} \mathrm{C}$ yielded $\alpha$-lactalbumin fibrils (Otte, Ipsen, Bauer, Bjerrum, \& Waninge, 2005; Otte, Ipsen, Ladefoged, $\&$ Sorensen, 2004). Furthermore, wheat gluten can form fibrillar structures with cross- $\beta$ structures after tryptic hydrolysis to an extent which depends on $\mathrm{pH}$, temperature, and ionic strength (Athamneh \& Barone, 2009b; Ridgley et al., 2012). Further, as already mentioned, food amyloids formed under acidic conditions often consist of peptides rather than of the intact protein, such as has been reported for hen egg white lysozyme and $\beta$-lactoglobulin (Akkermans et al., 2008; Frare et al., 2004; Oboroceanu, Wang, Brodkorb, Magner, \& Auty, 2010). Mishra et al. (2007) reported that for efficient incorporation of lysozyme into AFs it needs to be "nicked" (that is, it needs to have undergone hydrolysis of a peptide bond which does not affect the molecular weight because the peptide fragments formed are still cross-linked by disulfide bonds). Further hydrolysis of the peptides already incorporated in the fibrils formed by heating under acidic conditions can also take place by the so-called "fibril shaving process" (Mishra et al., 2007).

\section{Seeding \& Cross-Seeding Approaches to Tailor (Food) Protein Aggregation}

In some cases, adding preformed protein fibrils to a solution of the same protein, which is referred to as seeding (Figure 3 and 4), significantly accelerates fibril formation. More specifically, it shortens the lag phase in which fibrils are not detectable (Krebs et al., 2000). This demonstrates that fibril growth is dominated by a mechanism which includes a nucleation phase followed by linear growth. From the extensive studies of seeding in the context of protein aggregation pathologies such as in Alzheimer's disease, it has become clear that the molecular basis of the seeding reaction is the templating that occurs when a preformed seed "recruits" an additional molecule from the pool of soluble molecules. This process appears to be highly specific, both in terms of the sequence match between seed and added molecules (Ganesan et al., 2015; Krebs et al., 2000; O’Nuallain, Williams, Westermark, \& Wetzel, 2004) and in the detailed morphology of the aggregates (Sawaya et al., 2007). The latter gives rise to so-called strains of aggregates which consist of the same polypeptide but differ in how the individual chains pack together in the fibril backbone.

Seeding has also been reported for several food proteins but process parameters seem to play an important role. Fibril formation by hen lysozyme was substantially accelerated by adding aliquots of solutions in which either the full-length protein or its 49 to 64 peptide had previously formed fibrils to a fresh protein solution (Krebs et al., 2000). Sonication of preformed hen lysozyme fibrils into small particles and mixing a fraction thereof into a solution of fresh intact hen lysozyme allow immediate formation of secondgeneration AFs under conditions which, without seeding, only result in AF after a lag phase of 11 days (pH 2.2 at $57^{\circ} \mathrm{C}$; Sasaki et al., 2008). Temperature-dependent seeding has been reported for fibril formation of disulfide-reduced ovalbumin at $50{ }^{\circ} \mathrm{C}$ and neutral $\mathrm{pH}$ even though also without seeding there was no apparent lag phase (Kalapothakis et al., 2015). Hamada and Dobson (2002) showed that preformed $\beta$-lactoglobulin fibrils eliminate the lag phase for fibril formation of disulfide-reduced $\beta$-lactoglobulin in 3.0 to $5.0 \mathrm{~mol} / \mathrm{L}$ urea at $37^{\circ} \mathrm{C}$ and $\mathrm{pH} 7.0$. The same authors also performed "fragment seeding" studies in $5.0 \mathrm{M}$ urea at $\mathrm{pH}$ 7.0. Fibrils formed by one specific peptide (the $\beta$ A fragment) detectably accelerated fibril formation by full-length $\beta$-lactoglobulin (Hamada et al., 2009).

Fibril formation of proteins can also be accelerated by adding preformed fibrils of other proteins, which is referred to as crossseeding. Its efficiency strongly depends on sequence similarity. This suggests that long-range interactions are important for stabilizing the fibril core (Krebs, Morozova-Roche, Daniel, Robinson, \& Dobson, 2004). Peptides released from wheat gliadins by tryptic hydrolysis can be used as short hydrophobic "template" peptides to induce the self-assembly of larger $\alpha$-helical "adder" proteins such as $\alpha$-casein, $\alpha$-lactalbumin, amylase, hemoglobin, insulin, and myoglobin into $\mu \mathrm{m}$-sized protein fibers (Ridgley \& Barone, 2013; Ridgley et al., 2011; Ridgley et al., 2014). The hydrophobicity and the fraction of aliphatic amino acids in the $\alpha$-helices of the adder proteins affect their propensity to unfold into amyloid fibers and the morphology of the resulting fibers (Ridgley et al., 2014).

There are numerous reports of unsuccessful seeding attempts. Amyloid-like aggregation of BSA at 60 to $75^{\circ} \mathrm{C}$ at neutral $\mathrm{pH}$ is not accelerated by adding preformed aggregates, not even when these have been sonicated to disperse them and expose their growing ends (Holm et al., 2007). However, BSA fibril formation at $50{ }^{\circ} \mathrm{C}$ and $\mathrm{pH} 7.8$ can be accelerated by adding sonicated preformed fibrils of the intact protein (Stathopulos et al., 2004). Bolder, Sagis, Venema, and van der Linden (2007) reported that seeding is not successful for whey protein isolate (WPI) stirred during heating at $\mathrm{pH} 2.0$ and $80^{\circ} \mathrm{C}$. Attempts to improve the rate and yield of fibril formation of wheat gluten proteins at $\mathrm{pH}$ 6.0 to 7.0 in the presence of either $2.0 \mathrm{~mol} / \mathrm{L}$ urea or $30 \%(\mathrm{v} / \mathrm{v})$ trifluoroethanol by seeding with preformed insulin fibrils have been unsuccessful (Mackintosh et al., 2009). The failure of the approach was ascribed to the lack of sequence identity between the insulin seeds and the glutenin structure. The key determinant of successful seeding is the match between the sequence of the aggregation prone regions in the seeds and that of the polypeptide to be aggregated. The latter is impacted strongly by the availability of the aggregation prone region in the target protein. When this region is buried in the folded native structure of the protein, it cannot interact with the seed. Therefore, the efficiency of seeding depends on the ability to identify conditions where the target protein is at least partially denatured.

In conclusion, literature on seeding and cross-seeding in the context of food protein fibril formation is scarce. Given the unique techno-functional properties of amyloid-like fibrils and, hence, their potential for food structuring purposes, it is necessary to further explore seeding and cross-seeding of food proteins.

\section{Stability of (Food) Protein Fibrils}

Due to the extensive hydrogen bonding pattern and dry packing interface between their side chains, fibrils are probably the most stable structures adopted by polypeptides (Fitzpatrick, Knowles, Waudby, Vendruscolo, \& Dobson, 2011). They typically have much higher melting temperatures and detergent resistance than 


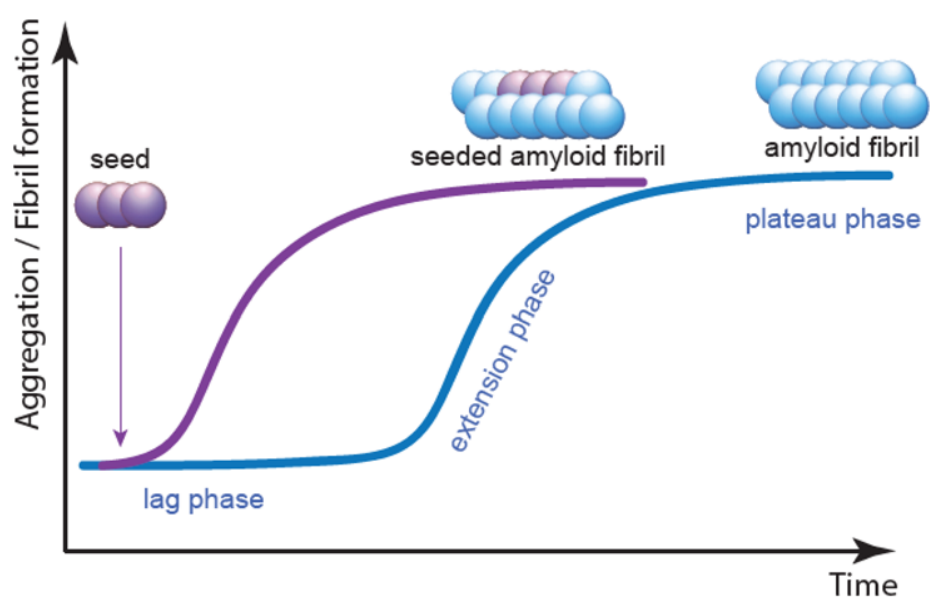

Figure 4-The impact of successful seeding on the formation of amyloid fibrils (AFs). Preformed aggregates result in a much shorter lag phase.

globular protein structures, but display a similar sensitivity to chaotropic agents (Fitzpatrick et al., 2011). Whereas fibril formation typically includes quite extreme conditions such as low $\mathrm{pH}$ and/or long heating times, milder conditions are mostly preferred in food applications. Furthermore, food preparation often involves several unit operations. Hence, the question arises whether the fibrils formed resist different conditions and food processing steps, especially those in which intense shear is applied such as in the formation of some foams and emulsions.

Veerman, de Schiffart, Sagis, and van der Linden (2003) showed that ovalbumin fibrils formed under acidic conditions do not fall apart upon dilution. In contrast, a $\mathrm{pH}$ change after fibril formation can have a strong effect. Indeed, a decrease in whey protein fibril length and increase in clustering was observed when increasing the $\mathrm{pH}$ from 2.0, the $\mathrm{pH}$ at which the fibrils were formed, to 7.0 to 8.0 (Akkermans, van der Goot, Venema, Van der Linden, \& Boom, 2008b; Wu et al., 2016). Changes in pH can also affect the turbidity of fibril solutions. At $\mathrm{pH} 2.0, \beta$-lactoglobulin fibril solutions are transparent. They become turbid at $\mathrm{pH} 5.0$ and again transparent at $\mathrm{pH}$ 8.0. Non-aggregated peptides formed during fibril formation have been identified as the main cause for the turbidity at pH 5.0 (Kroes-Nijboer et al., 2012). Loveday et al. (2011) observed that WPI fibrils are long and semi-flexible and that they have a smooth appearance at $\mathrm{pH} 2.0$, whereas after adjusting the $\mathrm{pH}$ to 6.7 , they appear to be shorter, thinner and to have a rough and irregular surface. In addition, there are generally less fibrils at $\mathrm{pH}$ 6.7. That a lot of small non-fibrillar protein aggregates are also present at this $\mathrm{pH}$ suggests that some fibrils have disintegrated into small aggregates. In a recent study, Mantovani, Fattori, Michelon, and Cunha (2016) observed a significant effect of soybean lecithin addition on whey protein fibril formation. Indeed, the secondary structure of fibrils formed in the presence or absence of soybean lecithin showed no differences or measurable differences, respectively, when increasing the $\mathrm{pH}$ from 3.0 to 7.0. Soybean lecithin did not affect fibril formation and conformation, but it decreased the susceptibility to $\mathrm{pH}$ changes.

Some authors have investigated the effect of shear on preformed fibrils. In general, it has been observed that limited shear promotes fibril formation whereas excessive shear or elongational strain when applied to preformed fibrils may lead to fibril shortening (Akkermans et al., 2006; Akkermans et al., 2008a; KroesNijboer, Venema, Baptist, \& van der Linden, 2010; Lieu et al.,
2007; Oboroceanu et al., 2011). Indeed, fracture of fibrils can produce shorter fibrils which, however, do not completely dissociate (Kroes-Nijboer et al., 2010; Oboroceanu et al., 2011). Fibril shortening also takes place upon application of rotor-stator dispersion and high pressure homogenization to WPI fibrils. Such processing techniques are used in the preparation of emulsions (Oboroceanu et al., 2011). Due to the reduction in size, the dispersions of the processed fibrils are transparent at $\mathrm{pH} 2.0$ and 3.0 (Serfert et al., 2014). Lyophilization followed by rehydration fractures semi-flexible straight fibrils into short rods, whereas highly flexible curly fibrils are hardly affected by these processing steps (Loveday, Su, Rao, Anema, \& Singht, 2012). As a result, dispersions of rehydrated straight fibril have a much lower viscosity than those of curly fibrils (Loveday et al., 2012). Fibril fracture does not necessarily negatively affect the functionality of protein fibrils. For example, Oboroceanu et al. (2014) reported that dynamic high (micro-fluidization) or moderate (Ultra-Turrax mixing) shear induced fracture of protein fibrils does not significantly affect their foaming properties.

\section{Steering Food Protein Techno-Functional Properties by Tailoring Fibril Aggregation}

We here discuss the importance of amyloid-like protein aggregation for the properties of food systems in general and for gelation, and interface properties in particular. More information on the link between other types of food protein aggregation and their techno-functional properties can be found elsewhere (Lam \& Nickerson, 2013; Mezzenga \& Fischer, 2013; Nicolai \& Durand, 2013; van der Linden \& Foegeding, 2009).

\section{The importance of amyloid-like aggregation for functional properties of food}

Proteins can form interfacial films that stabilize foams and emulsions (El-Salam, El-Shibiny, \& Salem, 2009; Lam \& Nickerson, 2013). The stability of foams and emulsions is often higher when heated rather than native proteins are used. This can be due to the effect of heat on protein unfolding, surface hydrophobicity, and/or aggregation (Nicolai \& Durand, 2013). Depending on the protein, the structure and the size of aggregates and solvent conditions, the foaming and emulsifying properties of dispersions containing protein aggregates differ from those of a solution containing non-aggregated proteins (Fameau \& Salonen, 2014; Lam 
\& Nickerson, 2013). In addition, (heat-induced) aggregation may affect the bulk properties of the protein solution, as for example, clearly seen in heat-induced protein gelation. Both the bulk and interfacial properties affect the structure and stability of dispersed systems such as emulsions and foams, but to extents which depend on the destabilization mechanism considered. For example, foam stability largely depends on drainage (which is slowed down by structure formation in the bulk liquid) and film rupture (which is mainly determined by interfacial properties; Fameau \& Salonen, 2014). Therefore, the foaming and emulsifying properties of fibrillar protein aggregates may vary from those of the original native proteins. Fibrillar structures (for example, polysaccharides and gelatin) occur in many food products and can increase viscosity, act as gelling agent and/or as stabilizer of foams and emulsions (Kroes-Nijboer et al., 2012). Therefore, it is reasonable to assume that amyloid-like fibrils also have functional properties relevant for food systems and their production.

\section{Functionality of protein amyloid fibrils in bulk liquid: gelation}

Globular proteins can form gels with either fine stranded or particulate morphologies (Nicolai \& Durand, 2013) which are mainly determined by the relative rates of unfolding and aggregation (Ferry, 1948). Particulate gels are either formed at a $\mathrm{pH}$ close to the iso-electric point or at high ionic strength and consist of randomly associated spheres. Fine stranded gels are formed when electrostatic repulsion between the proteins is high. They consist of cross-linked flexible strands and are often transparent at low ionic strength due to the strong mutual electrostatic repulsion which induces local order (Langton \& Hermansson, 1992; Nicolai \& Durand, 2013). In the presence of salt, the electrostatic interaction is screened to a certain extent. This yields more disordered gels which scatter light and thus are turbid (Ako, Durand, Nicolai, \& Becu, 2009; Mehalebi, Nicolai, \& Durand, 2008; Nicolai \& Durand, 2013). When the ionic strength decreases, this increases the minimal protein concentration necessary for gelation to occur (Bolisetty, Harnau, Jung, \& Mezzenga, 2012; Weijers, Visschers, \& Nicolai, 2004). Also $\mathrm{pH}$, temperature, protein concentration and type affect the gelation process (Gosal \& Ross-Murphy, 2000; Gosal, Clark, \& Ross-Murphy, 2004; Loveday et al., 2009; van Vliet, Martin, \& Bos, 2002). Clark, Kavanagh, and Ross-Murphy (2001) described the formation of homogeneous fine stranded gels as a process with three main stages: unfolding, linear fibrillary aggregation, and random association of fibrils. Because fine stranded gels consist of fibrils and are formed under conditions which resemble typical conditions for formation of amyloid-like structures, it is likely that they contain such aggregates. Ovalbu$\mathrm{min}$, for example, forms transparent gels after heating $\left(80^{\circ} \mathrm{C}\right.$, $80 \mathrm{~min}$ ) of protein solutions at a $\mathrm{pH}$ below 3.5 and at salt concentrations up to $30 \mathrm{mM}$ (Weijers, Sagis, Veerman, Sperber, \& van der Linden, 2002). Whey protein also forms transparent gels when heated under conditions typical for amyloid formation $\left(80^{\circ} \mathrm{C}\right.$ and $\mathrm{pH} 2.0$; Bolder, Hendrickx, Sagis, \& van der Linden, 2006b).

Factors that selectively affect amyloid formation can also affect the properties of protein gels. Kawachi et al. (2013) showed that the strength of ovalbumin gels prepared under acidic conditions is higher when prepared in the presence of the peptide corresponding to the $N$-terminal region (22 amino acid residues), which induces the formation of straight fibrils during heating as discussed above, than in its absence. Long before the link with amyloid-like aggregation was established, Kitabatake and Doi (1985) indicated its importance for protein gelation. They observed that gels formed by heating $\left(98^{\circ} \mathrm{C}\right.$, neutral $\left.\mathrm{pH}\right)$ ovalbumin or egg white solutions treated with pepsin (to remove a specific peptide) are transparent, whereas gels obtained under the same conditions from intact ovalbumin and intact egg white are turbid. Azakami, Mukai, and Kato (2005) reported lower gel strengths when ovalbumin gels were prepared at neutral $\mathrm{pH}$ in the presence of increasing levels of thioflavin $\mathrm{T}$ rather than in its absence. The authors suggested that thioflavin $\mathrm{T}$ binds to the cross- $\beta$ structure formed during heat denaturation of ovalbumin and thereby suppresses the formation of a further extended cross- $\beta$ structure. The gel strength was higher when a limited number of additional sulfhydryl groups were introduced in native ovalbumin, but lower again when more such groups were introduced. They further suggested that this was due to formation of covalent networks, which, once formed, cannot rearrange into a structure which leads to optimal gel strength (Broersen et al., 2006). According to Loveday et al. (2009) differences in rheological properties of protein gels composed of fibrils are probably related to the density and the persistence and contour length of the fibrils.

Next to heat-induced gelation, gelation at ambient temperature is possible for some proteins (Bryant \& Mcclements, 1998; Nicolai, Britten, \& Schmitt, 2011). The cold gelation is a two-step process. In a first step, a solution of native protein is heated at a $\mathrm{pH}$ far away from the isoelectric point and at low ionic strength. The obtained aggregates remain in solution during cooling. In a second step, gel formation is induced by reducing the electrostatic repulsion by charge shielding with salt or by adjusting the $\mathrm{pH}$ toward the isoelectric point of the proteins (Alting, de Jongh, Visschers, \& Simons, 2002; Alting, Hamer, de Kruif, \& Visschers, 2000; Bolder, Hendrickx, Sagis, \& Van der Linden, 2006a). Based on a study on cold-set gelation of whey proteins and ovalbumin, Alting et al. (2004) concluded that covalent bonds are the most important determinants of gel hardness. Different numbers of additional disulfide bonds were formed during gelation for both proteins because of the difference in the number and accessibility of reactive thiol groups. That long fibrillary structures of ovalbumin contribute significantly to gel hardness when thiol groups are blocked demonstrates that the aggregate shape can be important for the mechanical properties of protein gels (Alting et al., 2004). The strength of whey protein gels obtained by acid-induced gelation of preformed aggregates is higher for fibrillar than for spherical aggregates. Furthermore, thiolation of preformed aggregates decreases the concentration necessary for gelation and increases gel strength for WPI aggregates irrespective of whether they are fibrillar or spherical (Munialo, de Jongh, Broersen, van der Linden, \& Martin, 2013). Gel formation at low protein concentration can be induced by fibrillar aggregates. Indeed, salt-induced gelation from fibrillar $\beta$-lactoglobulin aggregates obtained by heating at $\mathrm{pH} 2$ followed by adjustment of the $\mathrm{pH}$ to 7 is possible at $\beta$ lactoglobulin concentrations as low as $0.07 \%$, whereas $1.4 \%$ is necessary for gelation to occur during heat treatment of the protein under the same conditions as those to prepare the fibrillar aggregates (Veerman, Sagis, \& van der Linden, 2003). Some authors wonder whether these structures should be called structured liquids rather than gels (Wu et al., 2016). Be that as it may, the critical gelation concentration for fibrillar aggregates is lower than that of non-fibrillar aggregates (Veerman et al., 2003; Wu et al., 2016) and depends strongly on the ionic strength of the protein solution (Bolisetty et al., 2012). Finally, adding transglutaminase to fibrillar and non-fibrillar $\beta$-lactoglobulin lowers the critical concentration for gelation and enhances the strength of gels probably 
as a result of the introduction of interconnections between fibrils by the enzyme (Wu et al., 2016).

\section{Functional properties of amyloid fibrils at interfaces}

Proteins can be important for stabilizing emulsions and foambased food products (Bos \& van Vliet, 2001; Lam \& Nickerson, 2013). Both the formation and stabilization of these emulsions and foams strongly depend on the interfacial properties of the proteins (and the presence of surfactants; Bos \& van Vliet, 2001; Sagis, 2011) which are affected by fibril formation (Jung, Gunes, \& Mezzenga, 2010; Patrick A. Rühs, Affolter, Windhab, \& Fischer, 2013).

As fibril formation generally leads to a complex mixture containing non-fibrillogenic peptides, denatured protein aggregates and fibrils, the question arises which fraction is most surface active, and which one preferentially accumulates at oil-water or air-water interfaces after emulsification or foam formation (Figure 5). Jung et al. (2010) reported that the surface tension at the air-water interface in the presence of $\beta$-lactoglobulin fibrils (obtained by heat treatment at $\mathrm{pH}$ 2) decreased more rapidly than that with native monomers. Interestingly, such behavior was not observed when unconverted monomers and peptides generated during fibril formation were removed by dialysis, inferring that their presence is the main explanation for the faster decrease of the surface tension. Here, protein adsorption was much faster at the oil-water than at the air-water interface (Jung et al., 2010). Serfert et al. (2014) and Jordens et al. (2014) also reported that fibrillar proteins decrease the interfacial tension more than the native proteins at the same concentration. In contrast, Rühs et al. (2013) and Humblet-Hua et al. (2013) reported a higher interfacial tension for solutions of $\beta$-lactoglobulin, lysozyme, and ovalbumin fibrils than for solutions of the native proteins. The differences in the effect of fibril formation on the interfacial tension of WPI and $\beta$-lactoglobulin solutions was attributed to the presence of other proteins besides $\beta$-lactoglobulin in WPI (Serfert et al., 2014). These results nicely demonstrate that it is difficult to rationalize the interfacial properties of protein fibrils as the presence of non-fibrillar protein material can drastically affect the results. This non-fibrillar material can saturate the interfacial layer and determine its properties (Mahmoudi, Gaillard, Boue, Axelos, \& Riaublanc, 2010).

The most common interfacial rheology measurements are surface dilatational and surface shear rheology. In shear rheology, a constant interfacial area is deformed by a sensor (such as a bicone) positioned within the interface, whereas in dilatational rheology the interfacial area is changed (Bos \& van Vliet, 2001; HumbletHua et al., 2013; Ravera, Loglio, \& Kovalchuk, 2010). A difficulty associated with the latter technique is that the area perturbation imposed by the measurement invokes structural changes of the adsorption layer (Mezzenga \& Fischer, 2013).

Interfacial shear rheology measurements have shown that the oil-water interface of systems containing $\beta$-lactoglobulin fibrils remains viscous for a certain time, but then quickly becomes mainly elastic. For native monomers, the interface becomes mainly elastic only considerable time after interface formation (Jung et al., 2010). Humblet-Hua et al. (2013) found higher surface shear as well as dilatational moduli for ovalbumin and lysozyme protein fibrils than for protein-pectin electrostatic complexes and the native proteins at oil-water interfaces. Serfert et al. (2014) also found a significantly higher elasticity (in dilatational interfacial rheology) at the oil-water interface for WPI fibrils than for native WPI at $\mathrm{pH} 2.0$ and 3.0. The increased interfacial activity was further reflected in an enhanced emulsifying activity. From interfacial rheology mea- surements, Jordens et al. (2014) also found that a highly elastic interface is formed in the presence of $\beta$-lactoglobulin fibrils. This is especially true at $\mathrm{pH} 2.0$, whereas at $\mathrm{pH} 3.0$ a nearly three times lower interfacial elastic modulus G' is measured. Moreover, films formed by long semi-flexible lysozyme or $\beta$-lactoglobulin fibrils have higher complex moduli than those formed from short rigid fibrils (Jung et al., 2010). Such differences were not picked-up with interfacial dilatational rheology measurements, whereas significant differences were observed with interfacial shear rheology experiments (Humblet-Hua et al., 2013).

Overall, the rheological properties of the interface depend on $\mathrm{pH}$ and ionic strength and are related to the charge on the protein and the shielding thereof (Jordens et al., 2014; Rühs et al., 2013; Rühs, Scheuble, Windhab, Mezzenga, \& Fischer, 2012). Rühs et al. (2012) studied the effect of an increase in sub-phase $\mathrm{pH}$ (from 2.0 to 6.0) on the interfacial rheology of $\beta$-lactoglobulin fibrils. They found that an increase in $\mathrm{pH}$ leads to an increase of both the interfacial storage and the loss moduli. That at the isoelectric point ( $\mathrm{pH} 5.0$ to 6.0) maximum storage and loss moduli were obtained was attributed to aggregation of the fibrils at the interface. When further increasing the $\mathrm{pH}$ above the iso-electric point, a decrease in visco-elasticity was noted and ascribed to increased electrostatic repulsion between the fibrils.

Finally, the question arises to what extent protein fibril formation can occur or be promoted by interfacial adsorption. In fact, it is well known that adsorption can induce globular protein unfolding (with the more hydrophobic and hydrophilic parts avoiding and trying to have contact with water, respectively). As structural reorganization is an essential sub-process in fibril formation, it follows that interfacial denaturation may promote fibril formation, both in the absence and presence of specific fibrilpromoting peptides. In this respect, Phoon, San Martin-Gonzalez, and Narsimhan (2014) observed that the thioflavin T fluorescence at the interfacial rim of oil droplets stabilized by both native soy $\beta$-conglycinin (7S) and tryptic hydrolysates was higher than that of the protein solutions used to prepare the emulsions. This may indicate that fibril formation was induced in these samples during emulsification. Whether this is indeed the case still needs to be verified (Phoon et al., 2014).

Overall, literature on the interfacial properties of protein fibrils is limited. Only a handful of proteins have been investigated and only under a limited number of $\mathrm{pH}$ and ionic strength conditions. Furthermore, the results strongly depend on the experimental setup (for example, the presence of non-fibrillar material) and it still needs to be investigated to what extent the model system experimental setups are relevant for real food systems.

\section{Functional properties of amyloid fibrils in foams and emulsions}

Because fibril formation of protein affects both the bulk and interfacial rheological properties, it can be expected that it also affects foam and emulsion formation and stability. Indeed, the foam and emulsion forming properties of proteins are determined by their ability to rapidly adsorb at the interface, which according to some authors is promoted indirectly in fibrillary dispersions by the presence of small and hence very mobile non-amyloidogenic peptides. However, the stability of foams and emulsions against coalescence mainly relies on the ability to form a cohesive viscoelastic interfacial film via intermolecular interactions that mechanically prevents the rupture of the thin film between adjacent air bubbles or oil droplets (Fameau \& Salonen, 2014; Lomakina \& Mikova, 2006). Moreover, both foam and emulsion stability may be 


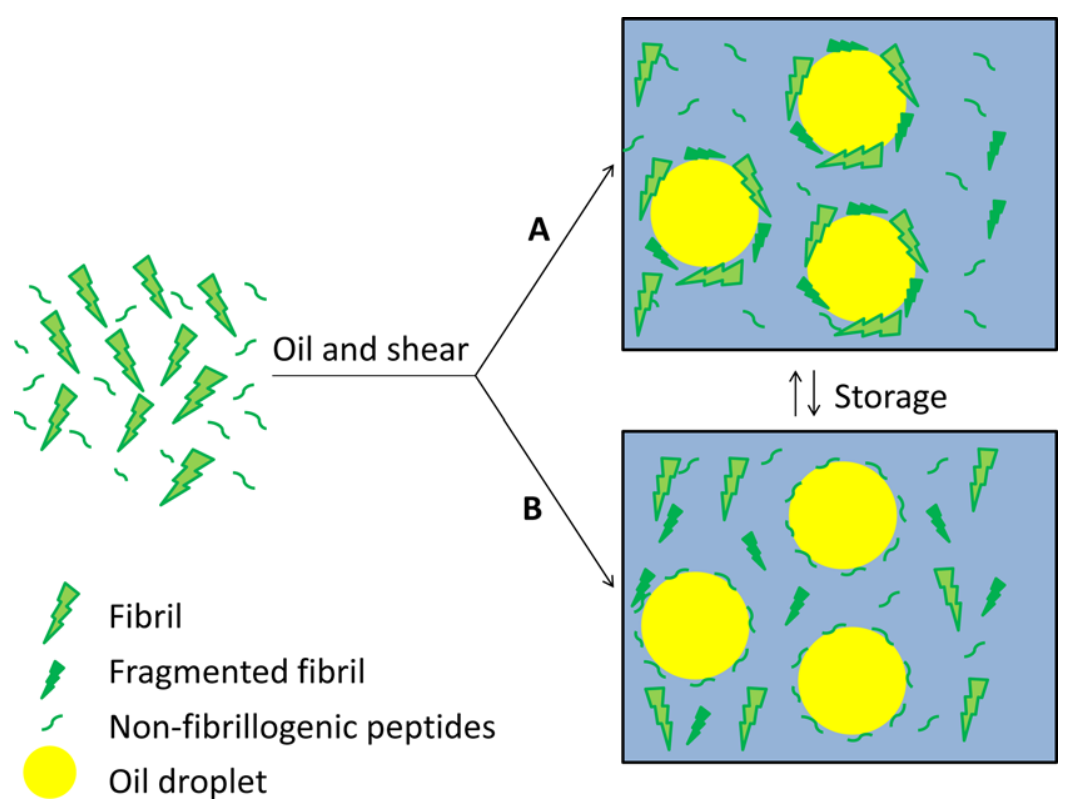

Figure 5-Schematic representation of emulsion formation from amyloid containing protein solutions. Because amyloid containing solutions typically consist of a complex mixture of fibrils and non-fibrillogenic material, the question arises whether fibrils (case A) or non-fibrillogenic material (case B) are most surface active. Furthermore, high-shear emulsification can induce fibril fracture. During storage of a freshly prepared emulsion displacement may also take place.

positively affected by increased structure formation in the aqueous continuous phase which slows down film thinning by drainage as well as de-mixing of the dispersion by creaming or sedimentation.

Little research has been performed on the effect of fibril formation (conditions) on the foaming properties of proteins. Whey protein fibrils have significantly better foaming capacity and stability compared to unheated and non-fibrillar heat denatured whey protein (Mohammadian \& Madadlou, 2016; Oboroceanu et al., 2014). Fibrillar whey proteins are highly effective foaming agents even at relatively low protein concentrations. In fact, their foaming properties are comparable to those of the traditional foaming ingredient egg white (Oboroceanu et al., 2014). Protein aggregation (by heating at $\mathrm{pH} 7.0$ ) improved the foaming characteristics but less so than when also fibrils were formed. However, it was not clear whether the improved foam stability is due to the enhanced viscosity of the continuous phase, or rather to the increased elasticity of the interface (Oboroceanu et al., 2014).

When globular proteins are used as emulsifiers, this is mainly for oil-in-water $(\mathrm{o} / \mathrm{w})$ emulsions. The emulsifier adsorbs at the oil-water interface of freshly formed fine oil droplets and prevents them from sticking together and subsequently coalescing with their neighbors to form larger droplets (Nishinari, Fang, Guo, \& Phillips, 2014). Serfert et al. (2014) reported that fibrils from WPI have a better emulsifying activity at a fixed oil content than native WPI itself. Considering that emulsification requires high shear, fibril shortening likely occurs during the emulsification process (Oboroceanu et al., 2011). According to Serfert et al. (2014) this may be positive with respect to the stabilization of interfaces in emulsions since the efficiency of covering around small oil droplets may be higher for fibril fragments than for long fibrils (Serfert et al., 2014).

That fibrillar aggregates can have an important effect on o/w emulsions has also been reported by Phoon et al. (2014). These authors prepared both acidic and tryptic hydrolysates of soy $\beta$ - conglycinin (7S) and used them for preparing emulsions. The acid hydrolysates contained not only non-fibrillar protein material but also fibrils. These not only surrounded the rim of the emulsified drops, but also caused inter-drop bridging. This was especially so for the large fibrils and resulted in destabilization of the emulsions. In fact, single surface-active elongated nanofibrils can interact with several oil droplets and/or air bubbles, so that they become physically bound together in a so-called "necklaceand-bead"-like morphology. As bridging is favored by long fibrils, this phenomenon may be counteracted by shear-induced fibril fragmentation.

A major drawback of globular protein stabilized emulsions is their sensitivity to heat at temperatures exceeding that at which the protein denatures. According to Moayedzadeh et al. (2015) whey protein fibrils can be exploited in the formation of heat-resistant protein-stabilized emulsions and nanoemulsions. Graveland-Bikker and de Kruif (2006) indeed found that $\alpha$ lactalbumin fibrils can withstand conditions similar to those used in pasteurization treatments. However, more effort is required to compare the interfacial behavior of fibrils with that of native and heat-denatured whey proteins (Moayedzadeh et al., 2015).

Protein fibrillary solutions can also be added to previously prepared emulsions. According to Blijdenstein, Veerman, and van der Linden (2004), $\beta$-lactoglobulin fibrils induce flocculation of oil droplets of an $\mathrm{o} / \mathrm{w}$ emulsion stabilized by $\beta$-lactoglobulin by a depletion mechanism. The minimum fibril concentration required for flocculation was lower for long than for short fibrils (Blijdenstein et al., 2004). However, upon further increasing the concentration of protein fibrils, the emulsions were stabilized and the minimum fibril concentration required for stabilization was again lower for long than for short fibrils (Peng, Simon, Venema, $\&$ van der Linden, 2016). In fact, the enhanced creaming at low and reduced creaming at higher concentrations were very similar to the effects of non-adsorbing polymers with a typical sequence 
of depletion flocculation at lower and depletion stabilization at higher concentrations.

Humblet-Hua, Scheltens, van der Linden, and Sagis (2011) used protein fibrils for forming capsules by a layer by layer technique. In these experiments, an o/w emulsion stabilized by ovalbumin fibrils was subsequently subjected to alternative treatments with high methoxyl pectin and protein fibrils. At $\mathrm{pH} 3.5$, the pectin was anionic and the protein fibrils were cationic. A similar layer by layer approach was used to prepare microcapsules with protein fibril reinforced shells (Humblet-Hua, van der Linden, \& Sagis, 2012). However, in this case, the original o/w emulsion was stabilized by native WPI and subsequent layers were deposited by alternating treatments with anionic protein-pectin complexes and cationic protein fibrils. In this research (Humblet-Hua et al., 2012), semiflexible ovalbumin fibrils, short and rod-like lysozyme fibrils, and long and semi-flexible lysozyme fibrils were compared. It was shown that the mechanical properties of the capsules can be tuned by varying the flexibility of the protein fibrils (Humblet-Hua et al., 2012). Hence, the stability against coalescence of protein-stabilized emulsions can be further improved by this layer by layer technique. This is especially important in the preparation of so-called "high internal phase emulsions," which enable introducing structure in completely liquid oils. As such, unsaturated fatty acids and triacyl glycerols can be used, which is beneficial from a nutritional and medical point of view.

In conclusion, a limited number of studies have clearly indicated that fibrillar proteins have functional properties and that there is a clear link between fibril techno-functional behavior and morphology. However, these studies also mainly have considered simple model systems with only a small number of ingredients. Clearly, much more research is necessary to establish whether protein fibrils are useful in complex food systems.

\section{Food Protein Amyloids Potentially Have Negative Health Impacts: True or False?}

We here provide a step-by-step overview of the different stages in the human digestive process which may modify food amyloid structures and thereby not only discuss the limited literature about food amyloid proteins in the gastrointestinal tract (GIT), but also the impact of similar conditions in other sites of the body.

\section{Proteolysis and the gastrointestinal fate of amyloid fibril protein structures}

Resistance against proteolysis during gastro-intestinal digestion (if any) is related to

(i) the type of protein;

(ii) the structure in which it enters the GIT (for example, in solution or as a solid, an emulsion or a gel; and

(iii) the physiological conditions in the GIT (Martos, Contreras, Molina, \& López-FandiÑo, 2010; Luo, Boom, \& Janssen, 2015).

Also aggregate morphology and gel type influence the extent of digestion as well as the nature of peptides released (Macierzanka et al., 2012; Nyemb et al., 2014a). For example, the extent of hydrolysis is greater for linear than for spherical ovalbumin aggregates (Nyemb et al., 2014a). Peptic and chymotryptic cleavages are favored by prior aggregation of ovalbumin regardless of the aggregate morphology, whereas tryptic cleavage is favored when ovalbumin aggregates are of a spherical-agglomerated type (Nyemb et al., $2014 \mathrm{~b})$. The overall extent of protein digestion is greater for egg white gels composed of spherical aggregates than for filamentous gels containing linear aggregates (Nyemb et al., 2016).

An important point to consider is that protein digestion may affect the potential pathogenicity of AFs. Indeed, cellular responses not only depend on the chemical composition or molecular properties of AFs, but also on their length, width and surface area. For example, the lengths of straight fibrils produced from human $\beta_{2}$-microglobulin negatively correlate with their ability to disrupt membranes and to reduce cell viability (Xue et al., 2009). Digestion processes affect the physical attributes of AFs and can directly interfere with their potential pathogenicity in several ways:

(i) they can enhance the solubility of fibrils by degrading the food matrix in which they are embedded, thereby increasing their pathogenicity (Glabe, 2006),

(ii) they can degrade the mature fibrils to oligomers with increased pathogenicity (Stefani, 2010), or

(iii) they can contribute to formation of new fibrils (Martinez et al., 2015; Suzuki, Someki, Adachi, Irie, \& Hattori, 1999).

Amyloid cores are, in general, more resistant towards peptidases than proteins in other conformations (Harrison et al., 2007). An example of the impact of fibril length of food-derived amyloid proteins has been published by Vieira et al. (2007). They reported that hen egg white lysozyme oligomers induce cytotoxicity towards rat neuronal cells in culture, whereas mature fibrils were declared non-toxic, which is in line with what is known for disease-related amyloids. Here, soluble oligomers formed at the early stages of protein aggregation are increasingly recognized as the main toxic species. Based on these results, the authors (Vieira et al., 2007) suggested that amyloid oligomers from different proteins share conformation-dependent structures that may be associated with a more generic cytotoxicity.

Another process that may influence the potential pathogenicity of food-derived AFs is oxidation. For instance, oxidation of methionine in $\kappa$-casein increases fibril formation under physiological conditions and lowers amyloid-associated viability of the adrenal gland PC-12 cell line. $\kappa$-Casein fibril formation can be counteracted by $\beta$-casein, but when $\kappa$-casein is oxidized, the inhibition by B-casein is less efficient (Koudelka, Dehle, Musgrave, Hoffmann, \& Carver, 2012).

Overall, the potential toxicity of food-derived amyloid proteins is not yet well understood, and may depend on the protein source. Lassé et al. (2016) showed that the viability of enterocyte-like Caco- 2 cells is only minimally modified by mature fibrils, prefibrillar aggregates, and sonicated fibrils derived from whey, soy, kidney bean, or egg white proteins. Prior to adding amyloidlike structures in food systems or stimulating their formation it is advisable to verify whether it is safe to apply such structures in products for human consumption. In addition, excessive protein degradation occurs in the GIT, which may affect the bioactivity of added amyloid structures.

To assess the impact of these digestive processes on amyloid toxicity, we give a step-by-step overview (graphically represented in Figure 6) of the different stages in the human digestive process which may modify amyloid structures, thereby not only discussing the limited literature about food amyloid proteins in the GIT, but also mentioning the impact of similar conditions at other sites of the body.

\section{Gastric digestion}

Because only very limited secretion of peptidases in the saliva occurs, protein degradation in the mouth in essence is restricted to 


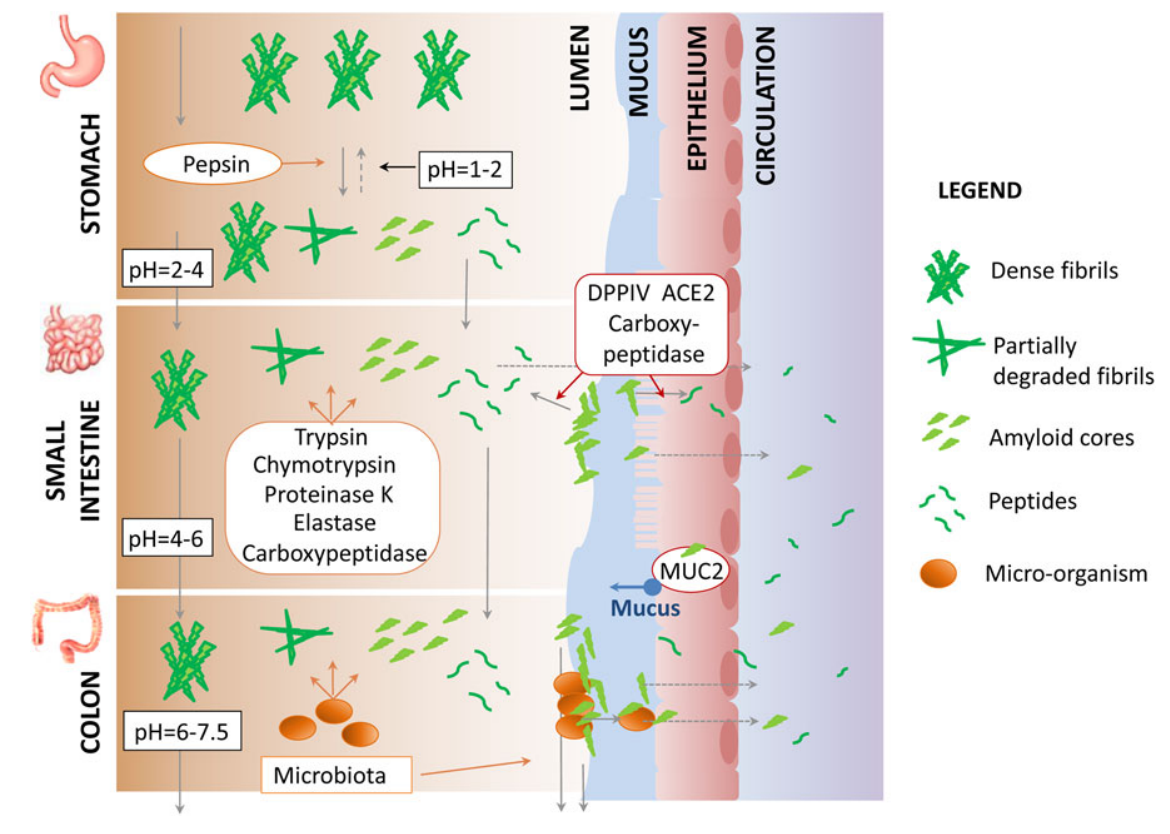

Figure 6-Graphical representation of the possible fate of amyloid fibrils (AFs) in the gastrointestinal tract. In the stomach, amyloid structures are subjected to a low $\mathrm{pH}$ and the digestive enzyme pepsin. In the small intestine, the pH gradually increases to about 6.5 by bicarbonate secretion, and luminal digestive enzymes (for example, trypsin) can cleave the remaining protein structures. Also mucus association and brush border enzymes at the intestinal level can play a role in the degradation of amyloid structures. Finally, microbiota in the colon produce a wide set of enzymes with proteolytic action.

mechanical breakdown of macromolecular structures. In contrast, the gastric environment, characterized by a low $\mathrm{pH}$ and the presence of the digestive enzyme pepsin may have a profound impact on AFs. The $\mathrm{pH}$ of the stomach during fasting conditions is about 1.5 to 2.0 , whereas it increases to above 4.0 while eating (Dressman et al., 1990). The stability of AFs against degradation is highly $\mathrm{pH}$ dependent and subtle differences in $\mathrm{pH}$ may have a strong effect (Tipping et al., 2015). At pH 6.5, $\beta 2$-microglobulin fibrils formed under acidic conditions disassemble and form fibril-derived nonnative spherical oligomers that disrupt synthetic membranes and alter cellular function. In contrast, fibril dissociation at $\mathrm{pH} 7.4$ results in non-toxic, native monomers (Tipping et al., 2015).

The effect of pepsin varies with the substrate. AFs produced from whey, kidney bean, soy bean, and egg ovalbumin are partially degraded by pepsin at $\mathrm{pH} 1.6$ with fibrils from whey protein being more resistant to hydrolysis than those from the other tested proteins (Lassé et al., 2016). In a similar experiment, Bateman, Ye, and Singh (2010) showed that long straight fibrils produced from $\beta$-lactoglobulin are swiftly degraded by pepsin at $\mathrm{pH} 1.2$. However, it must be noted that the conditions in the latter study deviated from physiological conditions (rather low $\mathrm{pH}$ and the $\mathrm{pH}$ typically increases when food enters the stomach). In a followup paper (Bateman, Ye, \& Singh, 2011), it was reported that after prolonged incubation new fibrils are formed from the degradation products of the original fibrils. These fibrils are long but thinner than the original fibrils. For the formation of these new fibrils a low $\mathrm{pH}$ is critical (Bateman et al., 2011). It should be pointed out that the $\mathrm{pH}$ and incubation times in this experiment were far from comparable to in vivo conditions. In a recent study, ironAFs hybrids (constructed from $\beta$-lactoglobulin) were subjected to acidic dissolution and enzymatic hydrolysis separately. The iron particles were no longer observed at acidic $\mathrm{pH}(\mathrm{pH} 1.2$ during 20 minutes), but the fibrils remained present. However, they were almost completely degraded after a pepsin digestion of $1 \mathrm{hr}$, thereby pointing to the importance of this enzyme to remove the fibril carrier of highly bioavailable iron nanoparticles (Shen et al., 2017).

AF formation during simulated gastro-intestinal conditions has also been observed by Martinez et al. (2015). They tested the effect of stomach ( $\mathrm{pH} 2.0$, pepsin 1/70, 10 minutes) and small intestinal digestion ( $\mathrm{pH} 7.5$, proteinase $\mathrm{K}: 1 / 70,30$ minutes) on the allergenic Atlantic cod $\beta$-parvalbumin, in the presence of calcium ions or ethylene diamine tetraacetic acid (EDTA). It was observed that gastric incubation (where $\mathrm{Ca}^{2+}$ binding is impeded as a result of protonation) initiates $\beta$-parvalbumin fibril formation both in the presence of calcium ions and EDTA. Under intestinal conditions, fibrils were only found under cationfree conditions. The same paper also reported on the prevention of fibril formation by epigallocatechin gallate, a polyphenol of green tea. These results illustrate the importance of the gastric step in AF formation during digestion, and the possible interference of (food) matrix compounds in this process. Some studies have reported on the interference of caffeine (Dall'Igna, Porciuncula, Souza, Cunha, \& Lara, 2003) and food phenolics such as oleuropein (Bazoti, Bergquist, Markides, \& Tsarbopoulos, 2008; Martorell et al., 2016) (in olive-derived food products), resveratrol (in wine; Han, Bastianetto, Dumont, \& Quirion, 2006), myricetin (in vegetables, fruits, nuts, berries, and tea; Fiori, Naldi, Bartolini, \& Andrisano, 2012) and bilberry extract (Choi, Kwon, Shin, \& Chung, 2014), with amyloid- $\beta$-peptide fibril formation and/or cytotoxicity in the context of Alzheimer's disease such as demonstrated in rat and mice studies (Choi et al., 2014; Han et al., 2006) and with isolated rat neuronal cells (Dall'Igna et al., 2003). In vitro studies using fluorescence spectroscopy with thioflavin $\mathrm{T}$ and electron microscopy have further demonstrated a dose-dependent inhibitory effect of myricetin, morin, quercetin, 
kaempferol, $(+)$-catechin, and (-)-epicatechin on the formation, extension, and destabilization of $\beta$-AFs at physiological conditions including a $\mathrm{pH} 7.5$ at $37^{\circ} \mathrm{C}$ (Ono et al., 2003). Some food constituents, such as the common environmental pollutant arsenic trioxide can promote self-assembly of hen egg white lysozyme under physiological conditions (Varma, Singh, Dahiya, Ravi, \& Kumar, 2018).

Overall, we conclude that the gastric environment may impact amyloid degradation and association with food compounds, thereby potentially influencing their potential cytotoxic effects. However, as the $\mathrm{pH}$ rapidly increases from two to more than three upon food product consumption, and food compounds - from protein as well as from other sources - may delay or even inhibit protein degradation by pepsin, AFs may escape the gastric digestion and reach the small intestine intact.

\section{Small intestinal digestion}

During small intestinal digestion, the luminal $\mathrm{pH}$ gradually increases to about 6.5 by bicarbonate secretion and luminal digestive enzymes (for example, trypsin) mostly secreted by the pancreas cleave the protein structures. The first report of amyloid susceptibility to trypsin was performed with the aim of unravelling fibril structure and composition of disease related amyloids. Emeson, Kikkawa, and Gueft (1966) prepared amyloid homogenates from livers of tuberculosis patients and digested the extracts with trypsin for up to $48 \mathrm{hr}$ at rather high $\mathrm{pH}(8.0)$. Electron microscopy revealed that enzymatic treatment of the fibrils resulted in a gradual shift from dense bundles of $100 \AA$ wide to a more disperse set of bundles of $40 \AA$ width. However, the morphology of the fibrils did not change over time. Although the applied conditions differ from those in the digestive system, the results showed a rather limited impact of trypsin on liver amyloids. In contrast, in vitro studies demonstrated the rapid degradation of fibrils produced from BSA when treated with trypsin at $\mathrm{pH} 7.4$ (Holm et al., 2007) although the applied conditions were not fully representative for physiological conditions in terms of digestive matrix, $\mathrm{pH}$, and temperature.

Pancreatin and proteinase $\mathrm{K}$ degrade whey, kidney bean, soy bean, and ovalbumin AFs at $\mathrm{pH} 7.5$ to an extent which depends on hydrolysis time, enzyme, and substrate (Lassé et al., 2016). The native fibrils showed no toxicity towards cell lines including intestinal Caco-2 and endometrial Hec-1a cells, except for kidney bean fibrils, which caused a slight decrease $(5 \%$ TO $10 \%)$ in viability of $\mathrm{Hec}-1 \mathrm{a}-$-epithelial cells. Intact and digested native fibrils increased the metabolic activity as tested with the WST-1 reagent with about $20 \%$. It is not clear whether this was due to increased cell proliferation or increased cellular stress, although the authors (Lassé et al., 2016) suggested that the cells may have been able to use these substrates as an energy source.

AFs isolated from tissues such as mammary and skin cancer cells and recombinant proteins including amyloid beta, A25T transthyretin (TTR), $\alpha$-synuclein ( $\alpha$-syn), and the prion Sup35 are susceptible to elastases (Skinner et al., 1986) such as produced locally by neutrophils (Azevedo et al., 2012). Elastase digestion of these AFs into short species strongly enhances their cell toxicity towards the hamster kidney BHK-21 cell line. Similarly, proteolytic processing of $\beta$-amyloid by carboxypeptidase $\mathrm{B}$ has earlier been reported in the context of Alzheimer's disease (Matsumoto, Itoh, \& Matsumoto, 2000; Matsumoto, Motozaki, Seki, Sasaki, \& Kawabe, 2001). So far, to the best of our knowledge, there are no reports about the susceptibility of food-derived AFs towards pancreatic chymotrypsin-like elastase one or carboxypeptidases.
Based on the above studies, it seems reasonable to assume that the luminal small intestinal environment favors AF degradation. Whether this affects the toxicity of food-based amyloids remains to be investigated.

\section{Mucin association}

The passage of amyloid structures through the mucus is one of the determinants of its exposure to the intestinal cells. Mucins are highly glycosylated proteins produced in the GIT that form a gel-like physical barrier for pathogens in the gut. They can be lost from the mucus layer by sloughing, by the slow action of endogenous peptidases, and by the action of enzymes of some gut bacteria (Gonzales, Van Camp, Smagghe, Raes, \& Mackie, 2016; Johansson \& Hansson, 2016). That mucin-like structures and amyloids associate, such as for example done by glycosaminoglycans in amyloid deposits in senile plaques, articular cartilage, and intervertebral discs has been reported by several authors and has been associated with the presence of sulfate groups in these structures (Athanasou, Kokubun, West, Sallie, \& Puddle, 1995; Athanasou, Puddle, \& Sallie, 1995; Fraser, Nguyen, Chin, \& Kirschner, 1992). Interestingly, serum amyloid A can upregulate the MUC2 gene in mouse colonic epithelial CMT-93 cells, thereby increasing mucin production by this cell line and affecting the barrier function of mucins (Shigemura, Ishiguro, \& Inoshima, 2014). Although no literature about the association of food-derived amyloid proteins with mucin is available, it seems possible that food-derived amyloids associate with gastro-intestinal mucins provided they survive the gastric and the luminal peptidases. If so, it is not clear what their impact on human intestinal health would be, as they may either be exfoliated and not reach the gastro-intestinal cells, or may penetrate through the mucus to reach the cells, where they would then be exposed to the brush border peptidases.

\section{Brush border enzymes}

No literature reports deal with the effect of brush border enzymes at the intestinal level on amyloid fibrillar structures (or their remnants). Nevertheless, many studies have reported on the impact of the same enzymes from neuronal origin on degradation of $\beta$-amyloid in the context of Alzheimer's disease (Mukherjee \& Hersh, 2002).

Glutamate carboxypeptidase II produced by neuronal and glial cells associates with and degrades $\beta$-amyloid peptides and therefore may play a role in the development of amyloid plaques in Alzheimer's disease (Kim, Chae, Koh, Lee, \& Jo, 2010; Lee et al., 2013), even if contradictory results exist (Alt, Stathis, Rojas, \& Slusher, 2013). An inverse correlation between the prevalence of glutamyl aminopeptidases in plasma and cerebrospinal fluid and Alzheimer's disease has been noted, thereby pointing to its possible role in $\beta$-amyloid catabolism (Kuda, Shoji, Arai, Kawashima, $\&$ Saido, 1997). $\beta$-Amyloid is also susceptible to a recombinant dipeptidyl carboxypeptidase angiotensin converting enzyme (ACE) 2 (ACE2; Sun et al., 2008). In vitro studies have shown that ACE2 actively participates in cleavage of $\beta$-amyloid into less toxic forms (Liu et al., 2014). This may explain the improved cognitive functions in mouse models of Alzheimer's disease after ACE inhibitor perindopril administration (Dong et al., 2011). Dipeptidyl peptidase IV associates with and cleaves $\beta$-amyloid peptide in vitro (Sharoyan et al., 2013). Also, dipeptidyl peptidase IV inhibitors prevent amyloid disposition in the brain of Alzheimer's prone mice (D'Amico et al., 2010) and $\beta$-amyloid induced cytotoxicity in SK-N-MC human neuronal cells, as well as mitochondrial dysfunction and increase of intracellular reactive oxygen 
species (ROS). They may therefore protect neuronal cells from amyloid impaired insulin signaling pathways (Kornelius et al., 2015). Based on these results, we may reasonably assume that brush-border enzymes produced by the intestinal cells may have impacts which are similar to those of the same enzymes produced in the neuronal environment, that is, the degradation of amyloid peptides, potentially released by luminal degradation of food fibrils, to less hazardous degradation products.

\section{Colonic microbial metabolism}

Colonic microbiota produce a wide set of proteolytic enzymes (Macfarlane, Cummings, \& Allison, 1986). However, as far as we know, their impact on AF degradation has not been studied. It is clear that microbial products such as tetracyclines can prevent amyloid formation (Forloni, Colombo, Girola, Tagliavini, $\&$ Salmona, 2001). Similarly, nattokinase, a peptidase produced by Bacillus subtilis, can degrade AFs of disease origin such as $\beta$ amyloid (Alzheimer's), huPrP (prion), and insulin-derived fibrils. It shares this ability with proteinase $\mathrm{K}$ and subtilisin but not with trypsin or plasmin (Hsu, Lee, Wang, Lee, \& Chen, 2009). These microbial-derived products are however not produced in the intestinal environment.

That micro-organisms have the potential to form amyloid structures on their cell surface has been reviewed by Pham et al. (2014). They listed the following microbial strains as forming amyloid-like structures: pathogenic bacteria including E. coli, Salmonella spp., Streptomyces coelicolor, Pseudomonas spp., Xanthomonas spp., Klebsiella pneumoniae, B. subtilis, Streptococcus mutans, Staphylococcus aureus, Mycobacterium tuberculosis, as well as yeasts and fungi, including Podospora anserina, Saccharomyces cerevisiae, and Candida albicans. Many of these microbial species are present in the gut, and mostly in disease-related contexts. Their cell-surface amyloids contribute to biofilm formation, host invasion, toxin formation and modulation of surface tension (Gorkovskii, Bezsonov, Plotnikova, Kalebina, \& Kulaev, 2009; Kalebina et al., 2008). In addition, Spirochaetesderived amyloid plaques have been reported in the context of brain functioning (Miklossy, 2016) and S. mutans is a functional amyloid-forming bacterium that forms oral microbial biofilms of dental caries (Oli et al., 2012). To summarize, these findings illustrate that AFs may be digested by microbial enzymes and may also have potential to act as a substrate for microbial biofilm formation, with possible impact on determinants of their pathogenesis such as host invasion and toxin production.

\section{Other studies}

Other studies have reported the impact of pre-digestion of food proteins at low $\mathrm{pH}$ and/or with gastro-intestinal enzymes on their fibril formation potential during $\mathrm{pH}$ decrease and/or heat incubation (Gao, Xu, Ju, \& Zhao, 2013; Picotti et al., 2007; Rao et al., 2011). In addition, digestive enzymes have been used to unravel the molecular characteristics and (food compound) interactions of amyloid structures (Bazoti et al., 2008; de Laureto et al., 2005; Frare et al., 2004, 2006; Syversen, Sletten, Marhaug, Husby, \& Lium, 1987). Although these studies illustrate the impact of for instance food processing on AF formation from non-disease related proteins (Aso et al., 2007), we have not discussed them here because the conditions which were applied are not relevant for normal gastro-intestinal digestion of food proteins.

Regretfully, all above food system-related studies were based on in vitro work. The potential toxicity has only been evaluated in vivo in two animal studies. In the first study (Solomon et al., 2007), a murine transgenic model of amyloid protein A (AA) amyloidosis, evoked by stimulus of the human IL-6 gene by methallothionein 1 (MT1) and/or histocompatibility H2-L, as well as wild type BALB/c mice subjected to an inflammatory stimulus thereby overexpressing apolipoprotein serum amyloid A were either injected or gavaged with $100 \mu \mathrm{g}$ amyloids extracted from "foie gras" per day during five consecutive days. Accelerated systemic pathological amyloid deposits in many organs, especially in liver and spleen were observed. This effect was reduced when cooking the "foie gras" product, thereby pointing to the importance of food processing in amyloid bioavailability. This is the first, but single report, demonstrating a potentially higher susceptibility to amyloidosis by consumption of certain food amyloids for a susceptible population. However, it should be stressed that the experimental setup involved a very invasive feeding procedure (injection in vein or gavage) of amyloid material from food proteins obtained under specific conditions (by extraction from "foie gras") and mice under rather acute inflammatory conditions (leading to susceptibility to amyloidosis). Therefore, it is highly questionable that the outcome of the results of this study on mice can be extrapolated to human consumption, even more so since "foie gras" is a common food product and no statistical correlation has been reported between its consumption and the prevalence of amyloidosis. Based on their results, the authors only indicate that it would seem prudent for a susceptible population (for example, adults with rheumatoid arthritis) to avoid such foods (Solomon et al., 2007).

In the second study (Shen et al., 2017), amyloid fibrils from $\beta$-lactoglobulin were used as carriers for iron nanoparticles and it was shown that these hybrid structures substantially increased iron bioavailability in rats. This study demonstrates the potential of well-designed and characterized amyloid fibrils to stabilize the redox status of the most bioavailable $\mathrm{Fe}^{2+}$ form. No adverse effects were reported upon a 14-day administration in rats $(n=10$ with $10 \mathrm{ppm}$ and $20 \mathrm{ppm}$ ), as concluded from histological examination of the salivary glands, lungs, thymus, hearth, liver, kidney, spleen, stomach, pancreas, small intestine, large intestine, brain, testes, mesenteric, and mediastinal lymph nodes, of a subset of each of the treatment groups. However, it should be noted that the primary outcome of this study was focused on iron bioavailability, and not on AF toxicity. Amyloid fibril formation in vivo is typically a very slow process when the test animals are not (made) highly sensitive to amyloidosis (for example, by inflammatory stimulus), which is the case here. In fact, even when pathological AF would have been used in this study, very likely no adverse effects would have been reported after extensive histological examination. Indeed, also pathological AF do not necessarily induce amyloidosis, especially in such a short time frame. For example, Eisele et al. (2009) reported that oral, intravenous, intraocular, or intranasal inoculations of brain extract containing misfolded $\beta$-amyloid (A $\beta$ ) failed to induce cerebral $\beta$-amyloidosis in a susceptible host (APP transgenic mice). Intraperitoneal injection of such brain extracts can induce cerebral $\beta$-amyloidosis in susceptible hosts, but only after prolonged incubation times (6 to 7 months; Eisele et al., 2010). Hence, as acknowledged by Shen et al. (2017), their study unfortunately does not allow to conclude that the AF which they used are food safe. The authors indeed stated that although their results suggested a lack of toxicity, specifically designed long-term toxicity studies are needed to confirm their findings. Furthermore, if confirmed with long-term toxicity studies, it also remains to be elucidated whether these results can be extrapolated to other types of AFs, humans, and in a food context. 
Based on the literature on the presence of AFs in "foie gras" (Solomon et al., 2007) and the ready conversion of food-derived proteins to the amyloid state by relatively straightforward manipulations, it seems likely that man consumes a significant amount of protein in the amyloid state. This knowledge in fact leads to the not so unlikely hypothesis that the very invention of food processing in the form of cooking and maybe also fermentation with all their known advantages also has inaugurated the regular consumption of denaturation-induced amyloid-structured protein. Notwithstanding the association of the amyloid structure with about thirty human diseases (Chiti \& Dobson, 2006; Harrison et al., 2007; Pham et al., 2014) the hypothesis that the amyloid structure is somehow intrinsically toxic (Bucciantini et al., 2002) is clearly not correct as we now increasingly appreciate the mechanical and functional advantages of amyloid conformation. Indeed, as indicated above, the amyloid structure is exploited by nature to perform a wide range of functions in organisms ranging from bacteria and yeasts up to humans (Egge et al., 2015; Fowler et al., 2007; Watt et al., 2013). However, this does not mean that food-based amyloids are by definition safe for human consumption. Nevertheless, based on the above we conclude that, if food-derived AFs with potential pathogenic properties would enter the GIT, their survival and impact on human health is expected to be limited because

(i) the $\mathrm{pH}$ reduction in the stomach in combination with the presence of pepsin would likely degrade the AF structure,

(ii) interactions with the food matrix, such as with phenolics and cations, would be expected,

(iii) a wide set of secreted and brush border peptidases would attack the fibril structure as well as their degradation products,

(iv) interaction with the sulfated regions of the protective mucin would be expected, and

(v) another set of peptidases, secreted by the intestinal microorganisms, may attack the fibril structures and their degradation products as well.

Yet, more research is needed to confirm the lack of toxicity of food-derived AFs, and to investigate whether harmful fibrils and degradation products are absorbed through the gastro-intestinal epithelia and may hence target other organs as well, which is currently unknown.

It is noteworthy that confirming that AFs are indeed safe for human consumption is important for all stakeholders in the chain from farm to fork due to the wide-spread association of amyloids with protein deposition diseases and the resultant perception of the safety of the technology. Indeed, in discussions with a range of stakeholders, we have observed major concerns regarding the safety of AFs. These concerns are mostly unfounded since there are currently little if any indications that consuming AFs could lead to protein misfolding diseases. Yet, these concerns clearly exist and, as extensively discussed, this body of scientific evidence simply does not suffice to declare that AFs are absolutely safe for consumption and, hence, to reassure the stakeholders. Furthermore, a major issue facing the food industry is the lack of trust of consumers in the processed foods. In fact, one of the six strategic objectives of EIT Food (the European Knowledge and Innovation Community, which was set up to transform our food ecosystem and involves businesses, research centers, universities, and consumers [EIT Food]) is exactly to overcome low consumer trust (EIT Food, n.d.). Also from this viewpoint, additional research to confirm the safety of AFs for consumption is highly desired prior to economical valorization.

\section{Conclusion and Perspectives}

The conformation of proteins has a great impact on their functionality in food products (Foegeding \& Davis, 2011; Nicolai \& Durand, 2013). Fibrillar protein structures such as AFs are particularly interesting (Kroes-Nijboer et al., 2012). Even though amyloid formation has been and is still mainly studied in a medical context, it appears to be a generic property of peptides (Rambaran \& Serpell, 2008) and it can take place under a range of conditions (Krebs et al., 2000; Swaminathan et al., 2011). Some of the conditions under which amyloids are formed are relevant for food processing. Therefore, it seems likely that food proteins in the amyloid state are already present in food products. Nevertheless, to the best of our knowledge, up to now the presence of amyloid structures in food products has only been reported for "foie gras" (Solomon et al., 2007) .

Whether or not and to what extent a protein forms amyloid-like structures depends on the presence of sequences that promote the formation of ordered aggregation, that is, the amyloid core regions (Chiti et al., 2002; de la Paz \& Serrano, 2004). Several prediction algorithms can be used to identify these core regions (ConchilloSole et al., 2007; Fernandez, Wiita, Ainavarapu, \& Huang, 2006; Maurer-Stroh et al., 2010; Trovato, et al., 2007). However, they are based on disease-related amyloids and may not be optimal for food protein-based amyloids. Furthermore, because the identification of amyloid core regions based on prediction algorithms has the intrinsic risk of being a self-feeding cycle that disregards the role of other, perhaps unexpected regions, other identification tools such as MS merit more attention. Mass spectrometric analysis is highly valuable for this purpose, but often very challenging. Up to now, only for a few food protein amyloids, the core regions have been studied. Nevertheless, understanding which sequences are part of the amyloid core region is of great importance, since soluble peptides corresponding to the amyloid core region can interfere with protein fibril formation (Kuroda et al., 2004; Tjernberg et al., 1996). Hence, approaches to selectively steer protein aggregation are possible with the correct peptides or peptide mixtures.

Another highly interesting approach to affect AF formation is seeding or cross-seeding. This involves the addition of preformed protein fibrils to a protein solution. Successful seeding approaches have only been realized for a handful of food proteins. Further research efforts are highly desirable. For practical application of AFs in real food systems, it is important to establish the stability of these preformed fibrils when subjected to changing environmental conditions and to food processing conditions. For example, the high shear treatment during formation of foams and emulsions may lead to fibril shortening which can affect its techno-functional properties (Akkermans et al., 2006, 2008a; Kroes-Nijboer et al., 2010; Lieu et al., 2007; Oboroceanu et al., 2011).

The techno-functional properties of protein aggregates often differ from those of nonaggregated proteins and the structure and size of the aggregates can play a role (Fameau \& Salonen, 2014; Lam \& Nickerson, 2013). Fine stranded gels containing fibrils are formed under conditions which resemble typical conditions for amyloid-like formation. Therefore, it is likely that amyloid-like aggregates are also present in such gels. Logically, factors that can selectively affect amyloid formation can also affect the properties of protein gels, but only few studies have applied such approaches. The literature on the interfacial properties of protein fibrils is rather limited and the results reported strongly depend on the 
experimental setup (for example, the presence of non-fibrillar material). Furthermore, it still needs to be established to what extent these experimental setups are relevant for real food systems, which are more complicated than the model systems which have been investigated until now (for example, presence of surfactants, sugar, other proteins). A few studies have demonstrated that fibril formation can improve the foaming capacity and stability and emulsifying activity of whey proteins (Mohammadian \& Madadlou, 2016; Oboroceanu et al., 2014; Serfert et al., 2014). However, much more research is necessary, for example to reveal whether the improved foam stability is due to the enhanced viscosity of the continuous phase, or rather to the increased elasticity of the interface. Furthermore, approaches to further improve the technofunctional properties by steering amyloid formation using the amyloid core regions or seeds are particularly interesting topics for further research. Although from the research discussed here it is clear that AFs have highly interesting techno-functional properties, the complexity of both food systems and protein aggregation suggest that much more research is necessary prior to optimal applications of amyloid technology in food products.

Among others, the aggregate morphology influences the extent of protein digestion as well as the nature of peptides released (Macierzanka et al., 2012; Nyemb et al., 2014a, 2014b, 2016). Changing the aggregate morphology by inducing or enhancing amyloid-like aggregation can thus affect the digestion process. Furthermore, even though amyloid formation seems to be a generic property of all peptides (Rambaran \& Serpell, 2008), the association of amyloid aggregation with several diseases raises the question on the potential toxicity of food-derived amyloids. Digestion processes can also affect the pathogenicity of AFs (Glabe, 2006; Martinez et al., 2015; Stefani, 2010; Suzuki et al., 1999). It is therefore advisable that the safety of applying such structures in food products is verified before adding or stimulating amyloid-like structures in real food systems.

A thorough literature review on the effect of the different stages of the human digestive process on amyloid toxicity suggests that even food-derived AFs with potential pathogenic properties will likely have minimal impact on human health. However, more research is needed to confirm the lack of toxicity of food-derived AFs and also to investigate whether harmful fibrils and degradation products are actually absorbed through the gastro-intestinal epithelia and may hence target other organs as well.

\section{Abbreviations \\ ACE2 angiotensin converting enzyme 2 \\ AF amyloid fibril \\ BSA bovine serum albumin \\ WPI whey protein isolate \\ XRD X-ray diffraction \\ Acknowledgments}

K. Brijs wishes to acknowledge the Industrial Research Fund (IOF, KU Leuven, Leuven, Belgium). I. Rombouts wishes to acknowledge the Research Foundation Flanders (FWO, Brussels, Belgium). J.A. Delcour is W.K. Kellogg Chair in Cereal Science and Nutrition at KU Leuven. This work is part of the Methusalem program "Food for the Future" (KU Leuven).

\section{Authors' Contributions}

Koen J.A. Jansens, Ine Rombouts, Charlotte Grootaert, and Paul Van der Meeren wrote the manuscript with critical input and corrections by Kristof Brijs, John Van Camp, Frederic Rousseau, Joost Schymkowitz, and Jan A. Delcour.

\section{References}

Adamcik, J., \& Mezzenga, R. (2011). Adjustable twisting periodic pitch of amyloid fibrils. Soft Matter, 7(11), 5437-5443.

https://doi.org/10.1039/C1sm05382e.

Adamcik, J., \& Mezzenga, R. (2012). Proteins fibrils from a polymer physics perspective. Macromolecules, 45(3), 1137-1150.

https://doi.org/10.1021/Ma202157h.

Akkermans, C., Van der Goot, A. J., Venema, P., Gruppen, H., Vereijken, J. M., Van der Linden, E., \& Boom, R. M. (2007). Micrometer-sized fibrillar protein aggregates from soy glycinin and soy protein isolate. Journal of Agricultural and Food Chemistry, 55(24), 9877-9882.

https://doi.org/10.1021/jf0718897.

Akkermans, C., van der Goot, A. J., Venema, P., van der Linden, E., \& Boom, R. M. (2008a). Formation of fibrillar whey protein aggregates: Influence of heat and shear treatment, and resulting rheology. Food Hydrocolloids, 22(7), 1315-1325. https://doi.org/10.1016/j.foodhyd.2007.07.001.

Akkermans, C., van der Goot, A. J., Venema, P., Van der Linden, E., \& Boom, R. M. (2008b). Properties of protein fibrils in whey protein isolate solutions: Microstructure, flow behavior and gelation. International Dairy Journal, 18(10-11), 1034-1042.

https://doi.org/10.1016/j.idairyj.2008.05.006

Akkermans, C., Venema, P., Rogers, S. S., van der Goot, A. J., Boom, R. M. \& van der Linden, E. (2006). Shear pulses nucleate fibril aggregation. Food Biophysics, 1(3), 144-150. https://doi.org/10.1007/s11483-006-9012-5.

Akkermans, C., Venema, P., van der Goot, A. J., Boom, R. M., \& van der Linden, E. (2008). Enzyme-induced formation of beta-lactoglobulin fibrils by AspN endoproteinase. Food Biophysics, 3(4), 390-394.

https://doi.org/10.1007/s11483-008-9094-3.

Akkermans, C., Venema, P., van der Goot, A. J., Gruppen, H., Bakx, E. J.,

Boom, R. M., \& van der Linden, E. (2008). Peptides are building blocks of heat-induced fibrillar protein aggregates of beta-lactoglobulin formed at $\mathrm{pH}$ 2. Biomacromolecules, 9(5), 1474-1479.

https://doi.org/10.1021/Bm7014224.

Ako, K., Durand, D., Nicolai, T., \& Becu, L. (2009). Quantitative analysis of confocal laser scanning microscopy images of heat-set globular protein gels. Food Hydrocolloids, 23(4), 1111-1119.

https://doi.org/10.1016/j.foodhyd.2008.09.003.

Alt, J., Stathis, M., Rojas, C., \& Slusher, B. (2013). Glutamate carboxypeptidase II is not an amyloid peptide-degrading enzyme. FASEB Journal, 27(7), 2620-2625. https://doi.org/10.1096/fj.12-225102.

Alting, A. C., de Jongh, H. H. J., Visschers, R. W., \& Simons, J. W. F. A. (2002). Physical and chemical interactions in cold gelation of food proteins. Journal of Agricultural and Food Chemistry, 50(16), 4682-4689. https://doi.org/10.1021/jf011657m.

Alting, A. C., Hamer, R. J., de Kruif, G. G., \& Visschers, R. W. (2000). Formation of disulfide bonds in acid-induced gels of preheated whey protein isolate. Journal of Agricultural and Food Chemistry, 48(10), 5001-5007. https://doi.org/10.1021/jf000474h.

Alting, A. C., Weijers, M., De Hoog, E. H. A., van de Pijpekamp, A. M., Stuart, M. A. C., Hamer, R. J., . . . Visschers, R. W. (2004). Acid-induced cold gelation of globular proteins: Effects of protein aggregate characteristics and disulfide bonding on rheological properties. Journal of Agricultural and Food Chemistry, 52(3), 623-631. https://doi.org/10.1021/Jf034753r.

Arnaudov, L. N., \& de Vries, R. (2005). Thermally induced fibrillar aggregation of hen egg white lysozyme. Biophysical Journal, 88(1), 515-526. https://doi.org/10.1529/biophysj.104.048819.

Arnaudov, L. N., \& de Vries, R. (2006). Strong impact of ionic strength on the kinetics of fibrilar aggregation of bovine beta-lactoglobulin. Biomacromolecules, 7(12), 3490-3498. https://doi.org/10.1021/Bm060584i.

Aso, Y., Shiraki, K., \& Takagi, M. (2007). Systematic analysis of aggregates from 38 kinds of non disease-related proteins: Identifying the intrinsic propensity of polypeptides to form amyloid fibrils. Bioscience Biotechnology and Biochemistry, 71(5), 1313-1321. https://doi.org/10.1271/Bbb.60718.

Assenza, S., Adamcik, J., Mezzenga, R., \& De Los Rios, P. (2014). Universal behavior in the mesoscale properties of amyloid fibrils. Physical Review Letters, 113(26), 268103.

https://doi.org/10.1103/PhysRevLett.113.268103.

Astbury, W.T., Dickinson, E., \& Bailey, K. (1935). The X-ray interpretation of denaturation and the structure of the seed globulins. Biochemical Journal, 29(10), 2351-2360. https://doi.org/10.1042/bj0292351.

Aterman, K. (1976). A historical note on the iodine-sulphuric acid reaction of amyloid. Histochemistry, 49(2), 131-143.

https://doi.org/10.1007/BF00495677. 
Athamneh, A. I., \& Barone, J. R. (2009a). Enzyme-mediated self-assembly of highly ordered structures from disordered proteins. Smart Materials \& Structures, 18(10). https://doi.org/10.1088/0964-1726/18/10/104024.

Athamneh, A., \& Barone, J. (2009b). Hierarchical self-assembly of tryptic peptides from wheat gluten. Paper presented at the ASME, Conference on Smart Materials, Adaptive Structures and Intelligent Systems (Oxnard, California, USA, September 21-23, 2009).

Athanasou, N. A., Kokubun, S., West, L., Sallie, B., \& Puddle, B. (1995). Glycosaminoglycans in intervertebral disc amyloid deposits. European Spine Journal, 4(5), 308-312.

Athanasou, N. A., Puddle, B., \& Sallie, B. (1995). Highly sulphated glycosaminoglycans in articular cartilage and other tissues containing beta 2 microglobulin dialysis amyloid deposits. Nephrology Dialysis Transplantation, 10(9), 1672-1678.

Azakami, H., Mukai, A., \& Kato, A. (2005). Role of amyloid type cross beta-structure in the formation of soluble aggregate and gel in heat-induced ovalbumin. Journal of Agricultural and Food Chemistry, 53(4), 1254-1257. https://doi.org/10.1021/Jf049325f.

Azevedo, E. P., Guimaraes-Costa, A. B., Torezani, G. S., Braga, C. A., Palhano, F. L., Kelly, J. W., ... Foguel, D. (2012). Amyloid fibrils trigger the release of neutrophil extracellular traps (NETs), causing fibril fragmentation by NET-associated elastase. Journal of Biological Chemistry, 287(44), 37206-37218. https://doi.org/10.1074/jbc.M112.369942.

Barlow, D. E., Dickinson, G. H., Orihuela, B., Kulp, J. L., 3rd, Rittschof, D., \& Wahl, K. J. (2010). Characterization of the adhesive plaque of the barnacle Balanus amphitrite: Amyloid-like nanofibrils are a major component. Langmuir, 26(9), 6549-6556. https://doi.org/10.1021/la9041309.

Bateman, L., Ye, A., \& Singh, H. (2010). In vitro digestion of beta-lactoglobulin fibrils formed by heat treatment at low $\mathrm{pH}$. Journal of Agricultural and Food Chemistry, 58(17), 9800-9808.

https://doi.org/10.1021/jf101722t.

Bateman, L., Ye, A., \& Singh, H. (2011). Re-formation of fibrils from hydrolysates of beta-lactoglobulin fibrils during in vitro gastric digestion. Journal of Agricultural and Food Chemistry, 59(17), 9605-9611. https://doi.org/10.1021/jf2020057.

Bazoti, F. N., Bergquist, J., Markides, K., \& Tsarbopoulos, A. (2008). Localization of the noncovalent binding site between amyloid-beta-peptide and oleuropein using electrospray ionization FT-ICR mass spectrometry. Journal of the American Society for Mass Spectrometry, 19(8), 1078-1085. https://doi.org/10.1016/j.jasms.2008.03.011.

Bednarska, N. G., Van Eldere, J., Gallardo, R., Ganesan, A., Ramakers, M., Vogel, I., ... Rousseau, F. (2016). Protein aggregation as an antibiotic design strategy. Molecular Microbiology, 99(5), 849-865.

https://doi.org/10.1111/mmi.13269.

Betti, C., Vanhoutte, I., Coutuer, S., De Rycke, R., Mishev, K., Vuylsteke, M., ... Russinova, E. (2016). Sequence-specific protein aggregation generates defined protein knockdowns in plants. Plant Physiology, 171(2), 773-787. https://doi.org/10.1104/pp.16.00335.

Blijdenstein, T. B. J., Veerman, C., \& van der Linden, E. (2004). Depletion-flocculation in oil-in-water emulsions using fibrillar protein assemblies. Langmuir, 20(12), 4881-4884.

https://doi.org/10.1021/la0497447.

Bolder, S. G., Hendrickx, H., Sagis, L. M. C., \& Van der Linden, E. (2006a). $\mathrm{Ca} 2+-$ induced cold-set gelation of whey protein isolate fibrils. Applied Rheology, 16(5), 258-264.

Bolder, S. G., Hendrickx, H., Sagis, L. M. C., \& van der Linden, E. (2006b). Fibril assemblies in aqueous whey protein mixtures. Journal of Agricultural and Food Chemistry, 54(12), 4229-4234. https://doi.org/10.1021/jf060606s.

Bolder, S. G., Sagis, L. M. C., Venema, P., \& van der Linden, E. (2007). Effect of stirring and seeding on whey protein fibril formation. Journal of Agricultural and Food Chemistry, 55(14), 5661-5669.

https://doi.org/10.1021/jf063351r.

Bolisetty, S., Harnau, L., Jung, J., \& Mezzenga, R. (2012). Gelation, phase behavior, and dynamics of $\beta$-lactoglobulin amyloid fibrils at varying concentrations and ionic strengths. Biomacromolecules, 13(10), 3241-3252. https://doi.org/10.1021/bm301005w.

Bos, M. A., \& van Vliet, T. (2001). Interfacial rheological properties of adsorbed protein layers and surfactants: A review. Advances in Colloid and Interface Science, 91(3), 437-471.

https://doi.org/10.1016/S0001-8686(00)00077-4.

Broersen, K., Van Teeffelen, A. M. M., Vries, A., Voragen, A. G. J., Hamer, R. J., \& De Jongh, H. H. J. (2006). Do sulfhydryl groups affect aggregation and gelation properties of ovalbumin? Journal of Agricultural and Food Chemistry, 54(14), 5166-5174. https://doi.org/10.1021/Jf0601923.
Bromley, E. H. C., Krebs, M. R. H., \& Donald, A. M. (2005). Aggregation across the length-scales in beta-lactoglobulin. Faraday Discussions, 128, 13-27. https://doi.org/10.1039/B403014a.

Bryant, C. M., \& McClements, D. J. (1998). Molecular basis of protein functionality with special consideration of cold-set gels derived from heat-denatured whey. Trends in Food Science \& Technology, 9(4), 143-151. https://doi.org/10.1016/S0924-2244(98)00031-4.

Bucciantini, M., Giannoni, E., Chiti, F., Baroni, F., Formigli, L., Zurdo, J. S., . Stefani, M. (2002). Inherent toxicity of aggregates implies a common mechanism for protein misfolding diseases. Nature, 416(6880), 507-511. https://doi.org/10.1038/416507a.

Chiti, F., \& Dobson, C. M. (2006). Protein misfolding, functional amyloid, and human disease. Annual Review of Biochemistry, 75, 333-366. https://doi.org/10.1146/annurev.biochem.75.101304.123901.

Chiti, F., Taddei, N., Baroni, F., Capanni, C., Stefani, M., Ramponi, G., \& Dobson, C. M. (2002). Kinetic partitioning of protein folding and aggregation. Nature Structural Biology, 9(2), 137-143. https://doi.org/10.1038/Nsb752.

Choi, Y. H., Kwon, H. S., Shin, S. G., \& Chung, C. K. (2014). Vaccinium uliginosum L. improves amyloid beta protein-induced learning and memory impairment in Alzheimer's disease in mice. Preventive Nutrition and Food Science, 19(4), 343-347. https://doi.org/10.3746/pnf.2014.19.4.343.

Clark, A. H., Kavanagh, G. M., \& Ross-Murphy, S. B. (2001). Globular protein gelation - theory and experiment. Food Hydrocolloids, 15(4-6), 383-400. https://doi.org/10.1016/S0268-005x(01)00042-X.

Conchillo-Sole, O., de Groot, N. S., Aviles, F. X., Vendrell, J., Daura, X., \& Ventura, S. (2007). AGGRESCAN: A server for the prediction and evaluation of "hot spots" of aggregation in polypeptides. BMC Bioinformatics, 8, 65. https://doi.org/10.1186/1471-2105-8-65.

D’Amico, M., Di Filippo, C., Marfella, R., Abbatecola, A. M., Ferraraccio, F., Rossi, F., \& Paolisso, G. (2010). Long-term inhibition of dipeptidyl peptidase-4 in Alzheimer's prone mice. Experimental Gerontology, 45(3), 202-207. https://doi.org/10.1016/j.exger.2009.12.004.

Dall'Igna, O. P., Porciuncula, L. O., Souza, D. O., Cunha, R. A., \& Lara, D. R. (2003). Neuroprotection by caffeine and adenosine A2A receptor blockade of beta-amyloid neurotoxicity. British Journal of Pharmacology, 138(7), 1207-1209. https://doi.org/10.1038/sj.bjp.0705185.

Das, S., Pal, U., Das, S., Bagga, K., Roy, A., Mrigwani, A., \& Maiti, N. C. (2014). Sequence complexity of amyloidogenic regions in intrinsically disordered human proteins. Plos One, 9(3), e89781.

https://doi.org/10.1371/journal.pone.0089781.

Dave, A. C., Loveday, S. M., Anema, S. G., Jameson, G. B., \& Singh, H.

(2014). Glycation as a tool to probe the mechanism of beta-lactoglobulin nanofibril self-assembly. Journal of Agricultural and Food Chemistry, 62(14), 3269-3278. https://doi.org/10.1021/jf405441g.

De Baets, G., Schymkowitz, J., \& Rousseau, F. (2014). Predicting aggregation-prone sequences in proteins. Essays in Biochemistry, 56, 41-52. https://doi.org/10.1042/bse0560041.

de la Paz, M. L., \& Serrano, L. (2004). Sequence determinants of amyloid fibril formation. Proceedings of the National Academy of Sciences of the United States of America, 101(1), 87-92. https://doi.org/10.1073/pnas.2634884100. de Laureto, P. P., Frare, E., Battaglia, F., Mossuto, M. F., Uversky, V. N., \& Fontana, A. (2005). Protein dissection enhances the amyloidogenic properties of alpha-lactalbumin. FEBS Journal, 272(9), 2176-2188. https://doi.org/10.1111/j.1742-4658.2005.04638.x.

Dong, Y. F., Kataoka, K., Tokutomi, Y., Nako, H., Nakamura, T., Toyama, K., ... Kim-Mitsuyama, S. (2011). Perindopril, a centrally active angiotensin-converting enzyme inhibitor, prevents cognitive impairment in mouse models of Alzheimer's disease. FASEB Journal, 25(9), 2911-2920. https://doi.org/10.1096/fj.11-182873.

Dressman, J. B., Berardi, R. R., Dermentzoglou, L. C., Russell, T. L., Schmaltz, S. P., Barnett, J. L., \& Jarvenpaa, K. M. (1990). Upper gastrointestinal (GI) pH in young, healthy men and women. Pharmaceutical Research, 7(7), 756-761.

Egge, N., Muthusubramanian, A., \& Cornwall, G. A. (2015). Amyloid properties of the mouse egg zona pellucida. Plos One, 10(6), e0129907. https://doi.org/10.1371/journal.pone.0129907.

Eisele, Y. S., Bolmont, T., Heikenwalder, M., Langer, F., Jacobson, L. H., Yan, Z. X., . . Jucker, M. (2009). Induction of cerebral beta-amyloidosis: Intracerebral versus systemic Abeta inoculation. Proceedings of the National Academy of Sciences of the United States of America, 106(31), 12926-12931. https://doi.org/10.1073/pnas.0903200106.

Eisele, Y. S., Obermuller, U., Heilbronner, G., Baumann, F, Kaeser, S. A., Wolburg, H., ... Jucker, M. (2010). Peripherally applied Abeta-containing 
inoculates induce cerebral beta-amyloidosis. Science, 330(6006), 980-982. https://doi.org/10.1126/science.1194516.

EIT Food, n.d. Retrieved from

http://www.eit.europa.eu/eit-community/eit-food Retrieved $14 / 04 / 2018$.

El-Salam, M. H. A., El-Shibiny, S., \& Salem, A. (2009). Factors affecting the functional properties of whey protein products: A review. Food Reviews International, 25(3), 251-270. https://doi.org/10.1080/87559120902956224.

Emeson, E. E., Kikkawa, Y., \& Gueft, B. (1966). New features of amyloid found after digestion with trypsin. Journal of Cell Biology, 28(3), 570-577.

Fameau, A. L., \& Salonen, A. (2014). Effect of particles and aggregated structures on the foam stability and aging. Comptes Rendus Physique, 15(8-9), 748-760. https://doi.org/10.1016/j.crhy.2014.09.009.

Fernandez-Escamilla, A. M., Rousseau, F, Schymkowitz, J., \& Serrano, L. (2004). Prediction of sequence-dependent and mutational effects on the aggregation of peptides and proteins. Nature Biotechnology, 22(10),

1302-1306. https://doi.org/10.1038/nbt1012.

Fernandez, J. M., Wiita, A. P., Ainavarapu, S. R. K., \& Huang, H. H. (2006) Force-dependent chemical kinetics of disulfide bond reduction observed with single-molecule techniques. Proceedings of the National Academy of Sciences of the United States of America, 103(19), 7222-7227. https://doi.org/10.1073/pnas.0511035103.

Ferry, J.D. (1948). Protein gels. Advances in Protein Chemistry, 4, 1-78. https://doi.org/10.1016/S0065-3233(08)60004-2.

Fiori, J., Naldi, M., Bartolini, M., \& Andrisano, V. (2012). Disclosure of a fundamental clue for the elucidation of the myricetin mechanism of action as amyloid aggregation inhibitor by mass spectrometry. Electrophoresis, 33(22), 3380-3386. https://doi.org/10.1002/elps.201200186.

Fitzpatrick, A. W., Knowles, T. P. J., Waudby, C. A., Vendruscolo, M., \& Dobson, C. M. (2011). Inversion of the balance between hydrophobic and hydrogen bonding interactions in protein folding and aggregation. Plos Computational Biology, 7(10).

https://doi.org/10.1371/journal.pcbi.1002169.

Foegeding, E. A., \& Davis, J. P. (2011). Food protein functionality: A comprehensive approach. Food Hydrocolloids, 25(8), 1853-1864. https://doi.org/10.1016/j.foodhyd.2011.05.008.

Forloni, G., Colombo, L., Girola, L., Tagliavini, F., \& Salmona, M. (2001). Anti-amyloidogenic activity of tetracyclines: Studies in vitro. FEBS Letters, 487(3), 404-407. https://doi.org/10.1016/S0014-5793(00)02380-2.

Fowler, D. M., Koulov, A. V., Balch, W. E., \& Kelly, J. W. (2007). Functional amyloid - from bacteria to humans. Trends in Biochemical Sciences, 32(5), 217-224. https://doi.org/10.1016/j.tibs.2007.03.003.

Frare, E., de Laureto, P. P., Zurdo, J., Dobson, C. M., \& Fontana, A. (2004). A highly amyloidogenic region of hen lysozyme. Journal of Molecular Biology, 340(5), 1153-1165. https://doi.org/10.1016/j.jmb.2004.05.056.

Frare, E., Mossuto, M. F., Polverino de Laureto, P., Dumoulin, M., Dobson, C. M., \& Fontana, A. (2006). Identification of the core structure of lysozyme amyloid fibrils by proteolysis. Journal of Molecular Biology, 361(3), 551-561. https://doi.org/10.1016/j.jmb.2006.06.055.

Fraser, P. E., Nguyen, J. T., Chin, D. T., \& Kirschner, D. A. (1992). Effects of sulfate ions on Alzheimer beta/A4 peptide assemblies: Implications for amyloid fibril-proteoglycan interactions. Journal of Neurochemistry, 59(4), 1531-1540. https://doi.org/10.1111/j.1471-4159.1992.tb08470.x.

Frousios, K. K., Iconomidou, V. A., Karletidi, C. M., \& Hamodrakas, S. J. (2009). Amyloidogenic determinants are usually not buried. BMC Structural Biology, 9, 44. https://doi.org/10.1186/1472-6807-9-44.

Gallardo, R., Ramakers, M., De Smet, F., Claes, F., Khodaparast, L.,

Couceiro, J. R., ... Rousseau, F. (2016). De novo design of a biologically active amyloid. Science, 354(6313), aah4949.

https://doi.org/10.1126/science.aah4949.

Ganesan, A., Debulpaep, M., Wilkinson, H., Van Durme, J., De Baets, G., Jonckheere, W., ... Rousseau, F. (2015). Selectivity of aggregation-determining interactions. Journal of Molecular Biology, 427(2), 236-247. https://doi.org/10.1016/j.jmb.2014.09.027.

Gao, Y. Z., Xu, H. H., Ju, T. T., \& Zhao, X. H. (2013). The effect of limited proteolysis by different proteases on the formation of whey protein fibrils. Journal of Dairy Science, 96(12), 7383-7392.

https://doi.org/10.3168/jds.2013-6843.

Garcia-Sherman, M. C., Lundberg, T., Sobonya, R. E., Lipke, P. N., \& Klotz, S. A. (2015). A unique biofilm in human deep mycoses: Fungal amyloid is bound by host serum amyloid P component. NPJ Biofilms Microbiomes, 1, 15009. https://doi.org/10.1038/npjbiofilms.2015.9.
Garcia-Sherman, M. C., Lysak, N., Filonenko, A., Richards, H., Sobonya, R. E., Klotz, S. A., \& Lipke, P. N. (2014). Peptide detection of fungal functional amyloids in infected tissue. Plos One, 9(1), e86067. https://doi.org/10.1371/journal.pone.0086067.

Gebbink, M. F., Claessen, D., Bouma, B., Dijkhuizen, L., \& Wosten, H. A. (2005). Amyloids-a functional coat for microorganisms. Nature Reviews Microbiology, 3(4), 333-341. https://doi.org/10.1038/nrmicro1127.

Ghadami, S. A., Khodarahmi, R., Ghobadi, S., Ghasemi, M., \& Pirmoradi, S. (2011). Amyloid fibril formation by native and modified bovine beta-lactoglobulins proceeds through unfolded form of proteins: A comparative study. Biophysical Chemistry, 159(2-3), 311-320.

https://doi.org/10.1016/j.bpc.2011.08.004.

Glabe, C. G. (2006). Common mechanisms of amyloid oligomer pathogenesis in degenerative disease. Neurobiology of Aging, 27(4), 570-575. https://doi.org/10.1016/j.neurobiolaging.2005.04.017.

Goldschmidt, L., Teng, P. K., Riek, R., \& Eisenberg, D. (2010). Identifying the amylome, proteins capable of forming amyloid-like fibrils. Proceedings of the National Academy of Sciences of the United States of America, 107(8), 3487-3492. https://doi.org/10.1073/pnas.0915166107.

Gonzales, G. B., Van Camp, J., Smagghe, G., Raes, K., \& Mackie, A. (2016). Flavonoid-gastrointestinal mucus interaction and its potential role in regulating flavonoid bioavailability and mucosal biophysical properties. Food Research International, 88, 342-347.

https://doi.org/10.1016/j.foodres.2015.12.023.

Gorkovskii, A. A., Bezsonov, E. E., Plotnikova, T. A., Kalebina, T. S., \& Kulaev, I. S. (2009). Revealing of Saccharomyces cerevisiae yeast cell wall proteins capable of binding thioflavin $\mathrm{T}$, a fluorescent dye specifically interacting with amyloid fibrils. Biochemistry (Moscow), 74(11), 1219-1224. https://doi.org/10.1134/S0006297909110066.

Gosal, W. S., Clark, A. H., \& Ross-Murphy, S. B. (2004). Fibrillar beta-lactoglobulin gels: Part 2. Dynamic mechanical characterization of heat-set systems. Biomacromolecules, 5(6), 2420-2429.

https://doi.org/10.1021/bm049660c.

Gosal, W. S., \& Ross-Murphy, S. B. (2000). Globular protein gelation. Current Opinion in Colloid \& Interface Science, 5(3-4), 188-194.

https://doi.org/10.1016/S1359-0294(00)00057-1.

Graether, S. P., Slupsky, C. M., \& Sykes, B. D. (2003). Freezing of a fish antifreeze protein results in amyloid fibril formation. Biophysical Journal, 84(1), 552-557. https://doi.org/10.1016/S0006-3495(03)74874-7.

Graveland-Bikker, J. F., \& de Kruif, C. G. (2006). Unique milk protein based nanotubes: Food and nanotechnology meet. Trends in Food Science $\mathcal{E}$

Technology, 17(5), 196-203. https://doi.org/10.1016/j.tifs.2005.12.009.

Hamada, D., \& Dobson, C. M. (2002). A kinetic study of beta-lactoglobulin amyloid fibril formation promoted by urea. Protein Science, 11(10), 2417-2426. https://doi.org/10.1110/Ps.0217702.

Hamada, D., Tanaka, T., Tartaglia, G. G., Pawar, A., Vendruscolo, M., Kawamura, M., ... Dobson, C. M. (2009). Competition between folding, native-state dimerisation and amyloid aggregation in beta-lactoglobulin. Journal of Molecular Biology, 386(3), 878-890.

https://doi.org/10.1016/j.jmb.2008.12.038

Hamodrakas, S. J. (2011). Protein aggregation and amyloid fibril formation prediction software from primary sequence: Towards controlling the formation of bacterial inclusion bodies. FEBS Journal, 278(14), 2428-2435. https://doi.org/10.1111/j.1742-4658.2011.08164.x.

Han, Y. S., Bastianetto, S., Dumont, Y., \& Quirion, R. (2006). Specific plasma membrane binding sites for polyphenols, including resveratrol, in the rat brain. Journal of Pharmacology and Experimental Therapeutics, 318(1), 238-245. https://doi.org/10.1124/jpet.106.102319.

Harrison, R. S., Sharpe, P. C., Singh, Y., \& Fairlie, D. P. (2007). Amyloid peptides and proteins in review. Reviews of Physiology Biochemistry and Pharmacology, 159, 1-77. https://doi.org/10.1007/112_2007_0701.

Hill, S. E., Miti, T., Richmond, T., \& Muschol, M. (2011). Spatial extent of charge repulsion regulates assembly pathways for lysozyme amyloid fibrils. Plos One, 6(4). https://doi.org/10.1371/journal.pone.0018171.

Hill, S. E., Robinson, J., Matthews, G., \& Muschol, M. (2009). Amyloid protofibrils of lysozyme nucleate and grow via oligomer fusion. Biophysical Journal, 96(9), 3781-3790. https://doi.org/10.1016/j.bpj.2009.01.044.

Holm, N. K., Jespersen, S. K., Thomassen, L. V., Wolff, T. Y., Sehgal, P., Thomsen, L. A., . . Otzen, D. E. (2007). Aggregation and fibrillation of bovine serum albumin. Biochimica et Biophysica Acta-Proteins and Proteomics, 1774(9), 1128-1138. https://doi.org/10.1016/j.bbapap.2007.06.008.

Hsu, R. L., Lee, K. T., Wang, J. H., Lee, L. Y., \& Chen, R. P. (2009).

Amyloid-degrading ability of nattokinase from Bacillus subtilis natto. Journal of 
Agricultural and Food Chemistry, 57(2), 503-508.

https://doi.org/10.1021/jf803072r.

Humblet-Hua, N. P. K., Sagis, L. M. C., \& van der Linden, E. (2008). Effects of flow on hen egg white lysozyme (HEWL) fibril formation: Length distribution, flexibility, and kinetics. Journal of Agricultural and Food Chemistry, 56(24), 11875-11882. https://doi.org/10.1021/Jf803377n.

Humblet-Hua, N. P. K., Scheltens, G., van der Linden, E., \& Sagis, L. M. C. (2011). Encapsulation systems based on ovalbumin fibrils and high methoxyl pectin. Food Hydrocolloids, 25(4), 569-576.

https://doi.org/10.1016/j.foodhyd.2011.01.003.

Humblet-Hua, N. P. K., van der Linden, E., \& Sagis, L. M. C. (2012). Microcapsules with protein fibril reinforced shells: Effect of fibril properties on mechanical strength of the shell. Journal of Agricultural and Food Chemistry, 60(37), 9502-9511. https://doi.org/10.1021/jf3024529.

Humblet-Hua, N. P. K., van der Linden, E., \& Sagis, L. M. C. (2013). Surface rheological properties of liquid-liquid interfaces stabilized by protein fibrillar aggregates and protein-polysaccharide complexes. Soft Matter, 9(7), 2154-2165. https://doi.org/10.1039/c2sm26627j.

Jansens, K. J. A., Brijs, K., Delcour, J. A., \& Scanlon, M. G. (2016). Amyloid-like aggregation of ovalbumin: Effect of disulfide reduction and other egg white proteins. Food Hydrocolloids, 61, 914-922. https://doi.org/10.1016/j.foodhyd.2016.07.015.

Jansens, K. J. A., Brijs, K., Stetefeld, J., Delcour, J. A., \& Scanlon, M. G. (2017). Ultrasound characterization of amyloid-like ovalbumin aggregation. ACS Omega, 2(8), 4612-4620. https://doi.org/10.1021/acsomega.7b00366.

Johansson, M. E., \& Hansson, G. C. (2016). Immunological aspects of intestinal mucus and mucins. Nature Reviews Immunology, 16(10), 639-649. https://doi.org/10.1038/nri.2016.88.

Jordens, S., Ruhs, P. A., Sieber, C., Isa, L., Fischer, P., \& Mezzenga, R. (2014). Bridging the gap between the nanostructural organization and macroscopic interfacial rheology of amyloid fibrils at liquid interfaces. Langmuir, 30(33), 10090-10097. https://doi.org/10.1021/la5020658.

Jung, J. M., Gunes, D. Z., \& Mezzenga, R. (2010). Interfacial activity and interfacial shear rheology of native beta-lactoglobulin monomers and their heat-induced fibers. Langmuir, 26(19), 15366-15375. https://doi.org/10.1021/la102721m.

Kalapothakis, J. M. D., Morris, R. J., Szavits-Nossan, J., Eden, K., Covill, S., Tabor, S., ... MacPhee, C. E. (2015). A kinetic study of ovalbumin fibril formation: The importance of fragmentation and end-joining. Biophysical Journal, 108(9), 2300-2311. https://doi.org/10.1016/j.bpj.2015. 03.021.

Kalebina, T. S., Plotnikova, T. A., Gorkovskii, A. A., Selyakh, I. O., Galzitskaya, O. V., Bezsonov, E. E., ... Kulaev, I. S. (2008). Amyloid-like properties of Saccharomyces cerevisiae cell wall glucantransferase Bgl2p: Prediction and experimental evidences. Prion, 2(2), 91-96. https://doi.org/10.4161/pri.2.2.6645.

Kavanagh, G. M., Clark, A. H., \& Ross-Murphy, S. B. (2000). Heat-induced gelation of globular proteins: Part 3. Molecular studies on low $\mathrm{pH}$ beta-lactoglobulin gels. International Journal of Biological Macromolecules, 28(1), 41-50. https://doi.org/10.1016/S0141-8130(00)00144-6.

Kawachi, Y., Kameyama, R., Handa, A., Takahashi, N., \& Tanaka, N. (2013). Role of the N-terminal amphiphilic region of ovalbumin during heat-induced aggregation and gelation. Journal of Agricultural and Food Chemistry, 61(36), 8668-8675. https://doi.org/10.1021/Jf402456v.

Kim, M. J., Chae, S. S., Koh, Y. H., Lee, S. K., \& Jo, S. A. (2010). Glutamate carboxypeptidase II: An amyloid peptide-degrading enzyme with physiological function in the brain. FASEB Journal, 24(11), 4491-4502. https://doi.org/10.1096/fj.09-148825.

Kitabatake, N., \& Doi, E. (1985). Heat-induced transparent gels prepared from pepsin-treated ovalbumin and egg-white. Agricultural and Biological Chemistry, 49(8), 2457-2458.

https://doi.org/10.1080/00021369.1985.10867102.

Knowles, T. P., Shu, W., Devlin, G. L., Meehan, S., Auer, S., Dobson, C. M., \& Welland, M. E. (2007). Kinetics and thermodynamics of amyloid formation from direct measurements of fluctuations in fibril mass. Proceedings of the National Academy of Sciences of the United States of America, 104(24), 10016-10021. https://doi.org/10.1073/pnas.0610659104.

Kornelius, E., Lin, C. L., Chang, H. H., Li, H. H., Huang, W. N., Yang, Y. S., ... Huang, C. N. (2015). DPP-4 inhibitor linagliptin attenuates abeta-induced cytotoxicity through activation of AMPK in neuronal cells. CNS Neuroscience \& Therapeutics, 21(7), 549-557. https://doi.org/10.1111/cns.12404.

Koudelka, T., Dehle, F. C., Musgrave, I. F., Hoffmann, P., \& Carver, J. A. (2012). Methionine oxidation enhances kappa-casein amyloid fibril formation. Journal of Agricultural and Food Chemistry, 60(16), 4144-4155. https://doi.org/10.1021/jf205168t.

Krebs, M. R. H., Morozova-Roche, L. A., Daniel, K., Robinson, C. V., \& Dobson, C. M. (2004). Observation of sequence specificity in the seeding of protein amyloid fibrils. Protein Science, 13(7), 1933-1938.

https://doi.org/10.1110/Ps.04707004.

Krebs, M. R. H., Wilkins, D. K., Chung, E. W., Pitkeathly, M. C., Chamberlain, A. K., Zurdo, J., ... Dobson, C. M. (2000). Formation and seeding of amyloid fibrils from wild-type hen lysozyme and a peptide fragment from the beta-domain. Journal of Molecular Biology, 300(3), 541-549. https://doi.org/10.1006/jmbi.2000.3862.

Krieger, E., Koraimann, G., \& Vriend, G. (2002). Increasing the precision of comparative models with YASARA NOVA-a self-parameterizing force field. Proteins, 47(3), 393-402. https://doi.org/10.1002/prot.10104.

Kroes-Nijboer, A., Sawalha, H., Venema, P., Bot, A., Floter, E., den Adel, R., ... van der Linden, E. (2012). Stability of aqueous food grade fibrillar systems against $\mathrm{pH}$ change. Faraday Discussions, 158, 125-138. https://doi.org/10.1039/c2fd20031g.

Kroes-Nijboer, A., Venema, P., Baptist, H., \& van der Linden, E. (2010). Fracture of protein fibrils as induced by elongational flow. Langmuir, 26(16), 13097-13101. https://doi.org/10.1021/la1025262.

Kroes-Nijboer, A., Venema, P., Bouman, J., \& van der Linden, E. (2011). Influence of protein hydrolysis on the growth kinetics of beta-lactoglobulin fibrils. Langmuir, 27(10), 5753-5761. https://doi.org/10.1021/la104797u.

Kroes-Nijboer, A., Venema, P., \& van der Linden, E. (2012). Fibrillar structures in food. Food \& Function, 3(3), 221-227.

https://doi.org/10.1039/C1fo10163c.

Kuda, T., Shoji, M., Arai, H., Kawashima, S., \& Saido, T. C. (1997). Reduction of plasma glutamyl aminopeptidase activity in sporadic Alzheimer's disease. Biochemical and Biophysical Research Communications, 231(3), 526-530. https://doi.org/10.1006/bbrc.1996.5920.

Kuroda, Y., Maeda, Y., Hanaoka, H., Miyamoto, K., \& Nakagawa, T. (2004) Oligopeptide-mediated acceleration of amyloid fibril formation of amyloid beta(A beta) and alpha-synuclein fragment peptide (NAC). Journal of Peptide Science, 10(1), 8-17. https://doi.org/10.1002/psc.485.

Lam, R. S. H., \& Nickerson, M. T. (2013). Food proteins: A review on their emulsifying properties using a structure-function approach. Food Chemistry, 141(2), 975-984. https://doi.org/10.1016/j.foodchem.2013.04.038.

Langton, M., \& Hermansson, A. M. (1992). Fine-stranded and particulate gels of beta-lactoglobulin and whey-protein at varying $\mathrm{pH}$. Food Hydrocolloids, 5(6), 523-539.

https://doi.org/10.1016/S0268-005X(09)80122-7.

Lara, C., Gourdin-Bertin, S., Adamcik, J., Bolisetty, S., \& Mezzenga, R. (2012). Self-assembly of ovalbumin into amyloid and non-amyloid fibrils. Biomacromolecules, 13(12), 4213-4221. https://doi.org/10.1021/Bm301481v.

Lara, C., Reynolds, N. P., Berryman, J. T., Xu, A. Q., Zhang, A. F., \& Mezzenga, R. (2014). ILQINS hexapeptide, identified in lysozyme left-handed helical ribbons and nanotubes, forms right-handed helical ribbons and crystals. Journal of the American Chemical Society, 136(12), 4732-4739. https://doi.org/10.1021/Ja500445z.

Lassé, Moritz, Ulluwishewa, Dulantha, Healy, Jackie, Thompson, Dion, Miller, Antonia, Roy, Nicole, ... Gerrard, Juliet A. (2016). Evaluation of protease resistance and toxicity of amyloid-like food fibrils from whey, soy, kidney bean, and egg white. Food Chemistry, 192, 491-498.

https://doi.org/10.1016/j.foodchem.2015.07.044.

Lee, S. K., Kim, H., Cheong, Y. H., Kim, M. J., Jo, S. A., Youn, H. S., \& Park, S. I. (2013). S1 pocket of glutamate carboxypeptidase II: A new binding site for amyloid-beta degradation. Biochemical and Biophysical Research Communications, 438(4), 765-771.

https://doi.org/10.1016/j.bbrc.2013.07.059.

Lefevre, T., \& Subirade, M. (2000). Molecular differences in the formation and structure of fine-stranded and particulate beta-lactoglobulin gels. Biopolymers, 54(7), 578-586.

https://doi.org/10.1002/1097-0282(200012)54:7<578::Aid-Bip100>3.0.Co;2-2.

Lieu, V. H., Wu, J. W., Wang, S. S. S., \& Wu, C. H. (2007). Inhibition of amyloid fibrillization of hen egg-white lysozymes by rifampicin and p-benzoquinone. Biotechnology Progress, 23(3), 698-706. https://doi.org/10.1021/Bp060353n.

Liu, S., Liu, J., Miura, Y., Tanabe, C., Maeda, T., Terayama, Y., ... Komano, H. (2014). Conversion of Abeta43 to Abeta40 by the successive action of angiotensin-converting enzyme 2 and angiotensin-converting enzyme. Journal of Neuroscience Research, 92(9), 1178-1186.

https://doi.org/10.1002/jnr.23404. 
Lomakina, K., \& Mikova, K. (2006). A study of the factors affecting the foaming properties of egg white - A review. Czech Journal of Food Sciences, 24(3), 110-118. https://doi.org/10.17221/3305-CJFS.

Loveday, S. M., Rao, M. A., Creamer, L. K., \& Singh, H. (2009). Factors affecting rheological characteristics of fibril gels: The case of beta-lactoglobulin and alpha-lactalbumin. Journal of Food Science, 74(3), R47-R55. https://doi.org/10.1111/j.1750-3841.2009.01098.x.

Loveday, S. M., Su, J. H., Rao, M. A., Anema, S. G., \& Singht, H. (2012). Whey protein nanofibrils: The environment-morphology-functionality relationship in lyophilization, rehydration, and seeding. Journal of Agricultural and Food Chemistry, 60(20), 5229-5236.

https://doi.org/10.1021/Jf300367k.

Loveday, S. M., Su, J., Rao, M. A., Anema, S. G., \& Singh, H. (2011). Effect of calcium on the morphology and functionality of whey protein nanofibrils. Biomacromolecules, 12(10), 3780-3788. https://doi.org/10.1021/bm201013b.

Loveday, S. M., Wang, X. L., Rao, M. A., Anema, S. G., \& Singh, H. (2012). beta-Lactoglobulin nanofibrils: Effect of temperature on fibril formation kinetics, fibril morphology and the rheological properties of fibril dispersions. Food Hydrocolloids, 27(1), 242-249.

https://doi.org/10.1016/j.foodhyd.2011.07.001.

Luo, Q., Boom, R. M., \& Janssen, A. E. M. (2015). Digestion of protein and protein gels in simulated gastric environment. LWT-Food Science and Technology, 63(1), 161-168. https://doi.org/10.1016/j.lwt.2015.03.087.

Macfarlane, G. T., Cummings, J. H., \& Allison, C. (1986). Protein degradation by human intestinal bacteria. Journal of General Microbiology, 132(6), 1647-1656. https://doi.org/10.1099/00221287-132-6-1647.

Macierzanka, A., Bottger, F., Lansonneur, L., Groizard, R., Jean, A. S.,

Rigby, N. M., . . Mackie, A. R. (2012). The effect of gel structure on the kinetics of simulated gastrointestinal digestion of bovine beta-lactoglobulin. Food Chemistry, 134(4), 2156-2163.

https://doi.org/10.1016/j.foodchem.2012.04.018.

Mackintosh, S. H., Meade, S. J., Healy, J. P., Sutton, K. H., Larsen, N. G., Squires, A. M., \& Gerrard, J. A. (2009). Wheat glutenin proteins assemble into a nanostructure with unusual structural features. Journal of Cereal Science, 49(1), 157-162. https://doi.org/10.1016/j.jcs.2008.08.003.

Mahmoudi, N., Gaillard, C., Boue, F., Axelos, M. A. V., \& Riaublanc, A. (2010). Self-similar assemblies of globular whey proteins at the air-water interface: Effect of the structure. Journal of Colloid and Interface Science, 345(1), 54-63. https://doi.org/10.1016/j.jcis.2010.01.036.

Mantovani, R. A., Fattori, J., Michelon, M., \& Cunha, R. L. (2016). Formation and $\mathrm{pH}$-stability of whey protein fibrils in the presence of lecithin. Food Hydrocolloids, 60, 288-298.

https://doi.org/10.1016/j.foodhyd.2016.03.039.

Martinez, J., Sanchez, R., Castellanos, M., Fernandez-Escamilla, A. M., Vazquez-Cortes, S., Fernandez-Rivas, M., \& Gasset, M. (2015). Fish beta-parvalbumin acquires allergenic properties by amyloid assembly. Swiss Medical Weekly, 145, w14128. https://doi.org/10.4414/smw.2015.14128.

Martorell, M., Forman, K., Castro, N., Capo, X., Tejada, S., \& Sureda, A. (2016). Potential therapeutic effects of oleuropein aglycone in Alzheimer's disease. Current Pharmaceutical Biotechnology, 17(11), 994-1001. Retrieved from https://doi.org/CPB-EPUB-77311.

Martos, G., Contreras, P., Molina, E., \& López-Fandino, R. (2010). Egg white ovalbumin digestion mimicking physiological conditions. Journal of Agricultural and Food Chemistry, 58(9), 5640-5648.

https://doi.org/10.1021/jf904538w.

Matsumoto, A., Itoh, K., \& Matsumoto, R. (2000). A novel carboxypeptidase $\mathrm{B}$ that processes native beta-amyloid precursor protein is present in human hippocampus. European Journal of Neuroscience, 12(1), 227-238. https://doi.org/10.1046/j.1460-9568.2000.00908.x.

Matsumoto, A., Motozaki, K., Seki, T., Sasaki, R., \& Kawabe, T. (2001). Expression of human brain carboxypeptidase $\mathrm{B}$, a possible cleaving enzyme for beta-amyloid precursor protein, in peripheral fluids. Neuroscience Research, 39(3), 313-317.

https://doi.org/10.1016/S0168-0102(00)00229-7.

Maurer-Stroh, S., Debulpaep, M., Kuemmerer, N., de la Paz, M. L., Martins, I. C., Reumers, J., ... Rousseau, F. (2010). Exploring the sequence determinants of amyloid structure using position-specific scoring matrices. Nature Methods, 7(10), 855-855. https://doi.org/10.1038/nmeth1010-855a.

Mehalebi, S., Nicolai, T., \& Durand, D. (2008). The influence of electrostatic interaction on the structure and the shear modulus of heat-set globular protein gels. Soft Matter, 4(4), 893-900. https://doi.org/10.1039/b718640a. Meisl, G., Kirkegaard, J. B., Arosio, P., Michaels, T. C., Vendruscolo, M., Dobson, C. M., ... Knowles, T. P. (2016). Molecular mechanisms of protein aggregation from global fitting of kinetic models. Nature Protocols, 11(2), 252-272.

https://doi.org/10.1038/nprot.2016.010nprot.2016.010[pii].

Mezzenga, R., \& Fischer, P. (2013). The self-assembly, aggregation and phase transitions of food protein systems in one, two and three dimensions. Reports on Progress in Physics, 76(4), 046601.

https://doi.org/10.1088/0034-4885/76/4/046601.

Miklossy, J. (2016). Bacterial amyloid and DNA are important constituents of senile plaques: Further evidence of the spirochetal and biofilm nature of senile plaques. Journal of Alzheimer's Disease, 53(4), 1459-1473.

https://doi.org/10.3233/JAD-160451.

Mishra, R., Sorgjerd, K., Nystrom, S., Nordigarden, A., Yu, Y. C., \& Hammarstrom, P. (2007). Lysozyme amyloidogenesis is accelerated by specific nicking and fragmentation but decelerated by intact protein binding and conversion. Journal of Molecular Biology, 366(3), 1029-1044. https://doi.org/10.1016/j.jmb.2006.11.084.

Moayedzadeh, S., Madadlou, A., \& Asl, A. K. (2015). Formation mechanisms, handling, and digestibility of food protein nanofibrils. Trends in Food Science \& Technology, 45(1), 50-59.

https://doi.org/10.1016/j.tifs.2015.05.005

Mohammadian, M., \& Madadlou, A. (2016). Characterization of fibrillated antioxidant whey protein hydrolysate and comparison with fibrillated protein solution. Food Hydrocolloids, 52, 221-230.

https://doi.org/10.1016/j.foodhyd.2015.06.022.

Morris, K. L., Rodger, A., Hicks, M. R., Debulpaep, M., Schymkowitz, J., Rousseau, F., \& Serpell, L. C. (2013). Exploring the sequence-structure relationship for amyloid peptides. Biochemical Journal, 450(2), 275-283. https://doi.org/10.1042/BJ20121773.

Mukherjee, A., \& Hersh, L. B. (2002). Regulation of amyloid beta-peptide levels by enzymatic degradation. Journal of Alzheimer's Disease, 4(5), 341-348. Munialo, C. D., de Jongh, H. H. J., Broersen, K., van der Linden, E., \& Martin, A. H. (2013). Modulation of the gelation efficiency of fibrillar and spherical aggregates by means of thiolation. Journal of Agricultural and Food Chemistry, 61(47), 11628-11635. https://doi.org/10.1021/Jf403723m.

Nakano, M., \& Kamino, K. (2015). Amyloid-like conformation and interaction for the self-assembly in barnacle underwater cement. Biochemistry, 54(3), 826-835. https://doi.org/10.1021/bi500965f.

Nicolai, T., Britten, M., \& Schmitt, C. (2011). Beta-Lactoglobulin and WPI aggregates: Formation, structure, and applications. Food Hydrocolloids, 25, 1945-1962. https://doi.org/10.1016/j.foodhyd.2011.02.006.

Nicolai, T., \& Durand, D. (2013). Controlled food protein aggregation for new functionality. Current Opinion in Colloid \& Interface Science, 18(4), 249-256. https://doi.org/10.1016/j.cocis.2013.03.001.

Nishinari, K., Fang, Y., Guo, S., \& Phillips, G. O. (2014). Soy proteins: A review on composition, aggregation and emulsification. Food Hydrocolloids, 39, 301-318. https://doi.org/10.1016/j.foodhyd.2014.01.013.

Nyemb, K., Guerin-Dubiard, C., Dupont, D., Jardin, J., Rutherfurd, S. M., $\&$ Nau, F. (2014a). The extent of ovalbumin in vitro digestion and the nature of generated peptides are modulated by the morphology of protein aggregates. Food Chemistry, 157, 429-438.

https://doi.org/10.1016/j.foodchem.2014.02.048.

Nyemb, K., Guerin-Dubiard, C., Pezennec, S., Jardin, J., Briard-Bion, V., Cauty, C., ... Nau, F. (2016). The structural properties of egg white gels impact the extent of in vitro protein digestion and the nature of peptides generated. Food Hydrocolloids, 54, 315-327.

https://doi.org/10.1016/j.foodhyd.2015.10.011.

Nyemb, K., Jardin, J., Causeur, D., Guerin-Dubiard, C., Dupont, D., Rutherfurd, S. M., \& Nau, F. (2014b). Investigating the impact of ovalbumin aggregate morphology on in vitro ovalbumin digestion using label-free quantitative peptidomics and multivariate data analysis. Food Research International, 63, 192-202. https://doi.org/10.1016/j.foodres.2014.03.041.

O’Nuallain, B., Williams, A. D., Westermark, P., \& Wetzel, R. (2004). Seeding specificity in amyloid growth induced by heterologous fibrils. Journal of Biological Chemistry, 279(17), 17490-17499. https://doi.org/10.1074/jbc.M311300200.

Oboroceanu, D., Wang, L. Z., Kroes-Nijboer, A., Brodkorb, A., Venema, P., Magner, E., \& Auty, M. A. E. (2011). The effect of high pressure microfluidization on the structure and length distribution of whey protein fibrils. International Dairy Journal, 21(10), 823-830.

https://doi.org/10.1016/j.idairyj.2011.03.015.

Oboroceanu, D., Wang, L. Z., Magner, E., \& Auty, M. A. E. (2014).

Fibrillization of whey proteins improves foaming capacity and foam stability at low protein concentrations. Journal of Food Engineering, 121, 102-111. https://doi.org/10.1016/j.jfoodeng.2013.08.023. 
Oboroceanu, D., Wang, L., Brodkorb, A., Magner, E., \& Auty, M. A. (2010). ECharacterization of $\beta$-lactoglobulin fibrillar assembly using atomic force microscopy, polyacrylamide gel electrophoresis, and in situ fourier transform infrared spectroscopy. Journal of Agricultural and Food Chemistry, 58(6), 3667-3673. https://doi.org/10.1021/jf9042908.

Oli, M. W., Otoo, H. N., Crowley, P. J., Heim, K. P., Nascimento, M. M., Ramsook, C. B., .. Brady, L. J. (2012). Functional amyloid formation by Streptococcus mutans. Microbiology, 158(Pt 12), 2903-2916.

https://doi.org/10.1099/mic.0.060855-0.

Ono, K., Yoshiike, Y., Takashima, A., Hasegawa, K., Naiki, H., \& Yamada, M. (2003). Potent anti-amyloidogenic and fibril-destabilizing effects of polyphenols in vitro: Implications for the prevention and therapeutics of Alzheimer's disease. Journal of Neurochemistry, 87(1), 172-181. https://doi.org/10.1046/j.1471-4159.2003.01976.x.

Otte, J., Ipsen, R., Bauer, R., Bjerrum, M. J., \& Waninge, R. (2005). Formation of amyloid-like fibrils upon limited proteolysis of bovine alpha-lactalbumin. International Dairy Journal, 15(3), 219-229. https://doi.org/10.1016/j.idairyj.2004.07.004.

Otte, J., Ipsen, R., Ladefoged, A. M., \& Sorensen, J. (2004). Protease-induced aggregation of bovine alpha-lactalbumin: Identification of the primary associating fragment. Journal of Dairy Research, 71(1), 88-96. https://doi.org/10.1017/S0022029903006617.

Ow, S. Y., \& Dunstan, D. E. (2013). The effect of concentration, temperature and stirring on hen egg white lysozyme amyloid formation. Soft Matter, 9(40), 9692-9701. https://doi.org/10.1039/C3sm51671g.

Pearce, F. G., Mackintosh, S. H., \& Gerrard, J. A. (2007). Formation of amyloid-like fibrils by ovalbumin and related proteins under conditions relevant to food processing. Journal of Agricultural and Food Chemistry, 55(2), 318-322. https://doi.org/10.1021/Jf062154p.

Peng, J. F., Simon, J. R., Venema, P., \& van der Linden, E. (2016). Protein fibrils induce emulsion stabilization. Langmuir, 32(9), 2164-2174. https://doi.org/10.1021/acs.langmuir.5b04341.

Pham, C. L., Kwan, A. H., \& Sunde, M. (2014). Functional amyloid: Widespread in nature, diverse in purpose. Essays in Biochemistry, 56, 207-219. https://doi.org/10.1042/bse0560207.

Phoon, P. Y., San Martin-Gonzalez, M. F., \& Narsimhan, G. (2014). Effect of hydrolysis of soy beta-conglycinin on the oxidative stability of $\mathrm{O} / \mathrm{W}$ emulsions. Food Hydrocolloids, 35, 429-443. https://doi.org/10.1016/j.foodhyd.2013.06.024.

Phoon, P. Y., San Martin-Gonzales, M. F., \& Ganesan, N. (2012). US Patent No. PCT/US2012/059034. Washington, D.C.: U.S. Patent and Trademark Office.

Picotti, P., De Franceschi, G., Frare, E., Spolaore, B., Zambonin, M., Chiti, F., ... Fontana, A. (2007). Amyloid fibril formation and disaggregation of fragment 1-29 of apomyoglobin: Insights into the effect of $\mathrm{pH}$ on protein fibrillogenesis. Journal of Molecular Biology, 367(5), 1237-1245. https://doi.org/10.1016/j.jmb.2007.01.072.

Pouzot, M., Nicolai, T., Visschers, R. W., \& Weijers, M. (2005). X-ray and light scattering study of the structure of large protein aggregates at neutral pH. Food Hydrocolloids, 19(2), 231-238. https://doi.org/10.1016/j.foodhyd.2004.06.003.

Raccosta, S., Martorana, V., \& Manno, M. (2012). Thermodynamic versus conformational metastability in fibril-forming lysozyme solutions. Journal of Physical Chemistry B, 116(40), 12078-12087. https://doi.org/10.1021/Jp303430g.

Rambaran, R. N., \& Serpell, L. C. (2008). Amyloid fibrils: Abnormal protein assembly. Prion, 2(3), 112-117. https://doi.org/10.4161/pri.2.3.7488.

Rao, S. P., Meade, S. J., Joyce, N. I., Healy, J. P., Sutton, K. H., Larsen, N. G., \& Gerrard, J. A. (2011). Amyloid fibril formation from crude protein mixtures. Biotechnology Progress, 27(6), 1768-1776. https://doi.org/10.1002/btpr.693.

Ravera, F, Loglio, G., \& Kovalchuk, V. I. (2010). Interfacial dilational rheology by oscillating bubble/drop methods. Current Opinion in Colloid E Interface Science, 15(4), 217-228.

https://doi.org/10.1016/j.cocis.2010.04.001.

Reynolds, N. P., Adamcik, J., Berryman, J. T., Handschin, S., Zanjani, A. A. H., Li, W., ... Mezzenga, R. (2017). Competition between crystal and fibril formation in molecular mutations of amyloidogenic peptides. Nature Communications, 8(1), 1338. https://doi.org/10.1038/s41467-01701424-4.

Ridgley, D. M., \& Barone, J. R. (2013). Evolution of the amyloid fiber over multiple length scales. Acs Nano, 7(2), 1006-1015.

https://doi.org/10.1021/Nn303489a.
Ridgley, D. M., Claunch, E. C., \& Barone, J. R. (2012). The effect of processing on large, self-assembled amyloid fibers. Soft Matter, 8(40), 10298-10306. https://doi.org/10.1039/C2sm26496j.

Ridgley, D. M., Claunch, E. C., Lee, P. W., \& Barone, J. R. (2014). The role of protein hydrophobicity in conformation change and self-assembly into large amyloid fibers. Biomacromolecules, 15(4), 1240-1247.

https://doi.org/10.1021/bm401815u.

Ridgley, D. M., Ebanks, K. C., \& Barone, J. R. (2011). Peptide mixtures can self-assemble into large amyloid fibers of varying size and morphology. Biomacromolecules, 12(10), 3770-3779.

https://doi.org/10.1021/Bm201005k.

Rousseau, F., Serrano, L., \& Schymkowitz, J. W. (2006). How evolutionary pressure against protein aggregation shaped chaperone specificity. Journal of Molecular Biology, 355(5), 1037-1047.

https://doi.org/10.1016/j.jmb.2005.11.035.

Rühs, P. A., Scheuble, N., Windhab, E. J., Mezzenga, R., \& Fischer, P. (2012). Simultaneous control of $\mathrm{pH}$ and ionic strength during interfacial rheology of beta-lactoglobulin fibrils adsorbed at liquid/liquid interfaces. Langmuir, 28(34), 12536-12543. https://doi.org/10.1021/la3026705.

Rühs, Patrick A., Affolter, Christine, Windhab, Erich J., \& Fischer, Peter. (2013). Shear and dilatational linear and nonlinear subphase controlled interfacial rheology of $\beta$-lactoglobulin fibrils and their derivatives. Journal of Rheology, 57(3), 1003-1022. https://doi.org/10.1122/1.4802051.

Sagis, L. M. C. (2011). Dynamic properties of interfaces in soft matter: Experiments and theory. Reviews of Modern Physics, 83(4), 1367-1403. https://doi.org/10.1103/RevModPhys.83.1367.

Sasahara, K., Yagi, H., Naiki, H., \& Goto, Y. (2007). Heat-induced conversion of beta(2)-microglobulin and hen egg-white lysozyme into amyloid fibrils. Journal of Molecular Biology, 372(4), 981-991. https://doi.org/10.1016/j.jmb.2007.06.088.

Sasaki, K., Nakatsuka, K., Hayashi, I., Shah, B. R., Morimoto, K., \& Akasaka, K. (2008). Efficient conversion of intact hen lysozyme into amyloid fibrils by seeding. Journal of Biological Macromolecules, 8(1), 11-18.

Sawaya, M. R., Sambashivan, S., Nelson, R., Ivanova, M. I., Sievers, S. A., Apostol, M. I., ... Eisenberg, D. (2007). Atomic structures of amyloid cross-beta spines reveal varied steric zippers. Nature, 447(7143), 453-457. https://doi.org/10.1038/nature05695.

Serfert, Y., Lamprecht, C., Tan, C. P., Keppler, J. K., Appel, E.,

Rossier-Miranda, F. J., . . S Schwarz, K. (2014). Characterisation and use of beta-lactoglobulin fibrils for microencapsulation of lipophilic ingredients and oxidative stability thereof. Journal of Food Engineering, 143, 53-61. https://doi.org/10.1016/j.jfoodeng.2014.06.026.

Sharoyan, S., Antonyan, A., Mardanyan, S., Harutyunyan, H., Movsisyan, N., Hovnanyan, N., \& Hovnanyan, K. (2013). Interaction of dipeptydil peptidase IV with amyloid peptides. Neurochemistry International, 62(8), 1048-1054. https://doi.org/10.1016/j.neuint.2013.03.017.

Sharp, J. S., Forrest, J. A., \& Jones, R. A. L. (2002). Surface denaturation and amyloid fibril formation of insulin at model lipid-water interfaces. Biochemistry, 41(52), 15810-15819. https://doi.org/10.1021/bi020525z.

Shen, Y., Posavec, L., Bolisetty, S., Hilty, F.M., Nyström, G., Kohlbrecher, J., Mezzenga, R. (2017). Amyloid fibril systems reduce, stabilize and deliver bioavailable nanosized iron. Nature Nanotechnology, 12, 642-647. https://doi.org/10.1038/nnano.2017.58.

Shigemura, H., Ishiguro, N., \& Inoshima, Y. (2014). Up-regulation of MUC2 mucin expression by serum amyloid A3 protein in mouse colonic epithelial cells. Journal of Veterinary Medical Science, 76(7), 985-991.

Sipe, J. D., \& Cohen, A. S. (2000). Review: History of the amyloid fibril. Journal of Structural Biology, 130(2-3), 88-98.

https://doi.org/10.1006/jsbi.2000.4221.

Skinner, M., Stone, P., Shirahama, T., Connors, L. H., Calore, J., \& Cohen, A. S. (1986). The association of an elastase with amyloid fibrils. Proceedings of the Society for Experimental Biologly and Medicine, 181(2), 211-214.

Solomon, A., Richey, T., Murphy, C. L., Weiss, D. T., Wall, J. S., Westermark, G. T., \& Westermark, P. (2007). Amyloidogenic potential of foie gras. Proceedings of the National Academy of Sciences of the United States of America, 104(26), 10998-11001.

https://doi.org/10.1073/pnas.0700848104.

Stathopulos, P. B., Scholz, G. A., Hwang, Y. M., Rumfeldt, J. A. O., Lepock, J. R., \& Meiering, E. M. (2004). Sonication of proteins causes formation of aggregates that resemble amyloid. Protein Science, 13(11), 3017-3027. https://doi.org/10.1110/Ps.04831804.

Stefani, M. (2010). Biochemical and biophysical features of both oligomer/fibril and cell membrane in amyloid cytotoxicity. FEBS Journal, 
277(22), 4602-4613. https://doi.org/10.1111/j.1742-4658.2010. 07889.x.

Sugimoto, Y., Kamada, Y., Tokunaga, Y., Shinohara, H., Matsumoto, M., Kusakabe, T., ... Ueda, T. (2011a). Aggregates with lysozyme and ovalbumin show features of amyloid-like fibrils. Biochemistry and Cell Biology-Biochimie Et Biologie Cellulaire, 89(6), 533-544.

https://doi.org/10.1139/O11-041.

Sugimoto, Yasushi, Kamada, Yoshiki, Tokunaga, Yuhei, Shinohara, Hiroshi, Matsumoto, Mitsuharu, Kusakabe, Takahiro, ... Ueda, Tadashi. (2011b). Aggregates with lysozyme and ovalbumin show features of amyloid-like fibrils. Biochemistry and Cell Biology, 89(6), 533-544. https://doi.org/10.1139/o11-041.

Sun, X., Becker, M., Pankow, K., Krause, E., Ringling, M., Beyermann, M. Siems, W. E. (2008). Catabolic attacks of membrane-bound angiotensin-converting enzyme on the N-terminal part of species-specific amyloid-beta peptides. European Journal of Pharmacology, 588(1), 18-25. https://doi.org/10.1016/j.ejphar.2008.03.058.

Sunde, M., Serpell, L. C., Bartlam, M., Fraser, P. E., Pepys, M. B., \& Blake, C. C. F. (1997). Common core structure of amyloid fibrils by synchrotron X-ray diffraction. Journal of Molecular Biology, 273(3), 729-739. https://doi.org/10.1006/jmbi.1997.1348.

Suzuki, Y., Someki, I., Adachi, E., Irie, S., \& Hattori, S. (1999). Interaction of collagen molecules from the aspect of fibril formation: Acid-soluble, alkali-treated, and MMP1-digested fragments of type I collagen. Journal of Biochemistr $\gamma$, 126(1), 54-67.

https://doi.org/10.1093/oxfordjournals.jbchem.a022436.

Swaminathan, R., Ravi, V. K., Kumar, S., Kumar, M. V. S., \& Chandra, N. (2011). Lysozyme: A model protein for amyloid research. Advances in Protein Chemistry and Structural Biology, 84, 63-111.

https://doi.org/10.1016/B978-0-12-386483-3.00003-3.

Syversen, V., Sletten, K., Marhaug, G., Husby, G., \& Lium, B. (1987). The amino acid sequence of serum amyloid A (SAA) protein in mink.

Scandinavian Journal of Immunology, 26(6), 763-767.

https://doi.org/10.1111/j.1365-3083.1987.tb02314.x.

Takai, E., Uda, K., Matsushita, S., Shikiya, Y., Yamada, Y., Shiraki, K., .. Maeda, M. (2014). Cysteine inhibits amyloid fibrillation of lysozyme and directs the formation of small worm-like aggregates through non-covalent interactions. Biotechnology Progress, 30(2), 470-478.

https://doi.org/10.1002/Btpr.1866.

Tanaka, N., Morimoto, Y., Noguchi, Y., Tada, T., Waku, T., Kunugi, S., . Takahashi, N. (2011). The mechanism of fibril formation of a non-inhibitory serpin ovalbumin revealed by the identification of amyloidogenic core regions. Journal of Biological Chemistry, 286(7), 5884-5894. https://doi.org/10.1074/jbc.M110.176396.

Tang, C. H., \& Wang, C. S. (2010). Formation and characterization of amyloid-like fibrils from soy beta-conglycinin and glycinin. Journal of Agricultural and Food Chemistry, 58(20), 11058-11066. https://doi.org/10.1021/jf1021658.

Tartaglia, G. G., \& Vendruscolo, M. (2008). The Zyggregator method for predicting protein aggregation propensities. Chemical Society Reviews, 37(7), 1395-1401. https://doi.org/10.1039/b706784b.

Thirumalai, D., Reddy, Govardhan, \& Straub, John E. (2012). Role of water in protein aggregation and amyloid polymorphism. Accounts of Chemical Research, 45(1), 83-92. https://doi.org/10.1021/ar2000869.

Thompson, M. J., Sievers, S. A., Karanicolas, J., Ivanova, M. I., Baker, D., \& Eisenberg, D. (2006). The 3D profile method for identifying fibril-forming segments of proteins. Proceedings of the National Academy of Sciences of the United States of America, 103(11), 4074-4078.

https://doi.org/10.1073/pnas.0511295103.

Tipping, K. W., Karamanos, T. K., Jakhria, T., Iadanza, M. G., Goodchild, S. C., Tuma, R., ... Radford, S. E. (2015). pH-induced molecular shedding drives the formation of amyloid fibril-derived oligomers. Proceedings of the National Academy of Sciences of the United States of America, 112(18), 5691-5696. https://doi.org/10.1073/pnas.1423174112.

Tjernberg, L. O., Naslund, J., Lindqvist, F., Johansson, J., Karlstrom, A. R., Thyberg, J., ... Nordstedt, C. (1996). Arrest of beta-amyloid fibril formation by a pentapeptide ligand. Journal of Biological Chemistry, 271(15), 8545-8548. https://doi.org/10.1074/jbc.271.15.8545.

Tokunaga, Y., Sakakibara, Y., Kamada, Y., Watanabe, K., \& Sugimoto, Y. (2013). Analysis of core region from egg white lysozyme forming amyloid fibrils. International Journal of Biological Sciences, 9(2), 219-227. https://doi.org/10.7150/Ijbs.5380.
Trovato, A., Seno, F., \& Tosatto, S. C. E. (2007). The PASTA server for protein aggregation prediction. Protein Engineering Design \& Selection, 20(10), 521-523. https://doi.org/10.1093/protein/gzm042.

van der Linden, E., \& Foegeding, E. A. (2009). Chapter 2: Gelation: principles, models and applications to proteins A2 - Kasapis, Stefan. In Ian T. Norton \& Johan B. Ubbink (Eds.), Modern biopolymer science (pp. 29-91). San Diego: Academic Press.

van Vliet, T., Martin, A. H., \& Bos, M. A. (2002). Gelation and interfacial behaviour of vegetable proteins. Current Opinion in Colloid \& Interface Science, 7(5-6), 462-468. https://doi.org/10.1016/S1359-0294(02)00078-X.

Varma, N., Singh, I., Dahiya, M. S., Ravi, V. K., \& Kumar, S. (2018).

Structural perturbation by arsenic triggers the aggregation of hen egg white lysozyme by promoting oligomers formation. International Journal of Biological Macromolecules, 109, 1108-1114.

https://doi.org/10.1016/j.ijbiomac.2017.11.096.

Veerman, C., de Schiffart, G., Sagis, L. M. C., \& van der Linden, E. (2003). Irreversible self-assembly of ovalbumin into fibrils and the resulting network rheology. International Journal of Biological Macromolecules, 33(1-3), 121-127. https://doi.org/10.1016/S0141-8130(03)00076-X.

Veerman, C., Ruis, H., Sagis, L. M. C., \& van der Linden, E. (2002). Effect of electrostatic interactions on the percolation concentration of fibrillar beta-lactoglobulin gels. Biomacromolecules, 3(4), 869-873.

https://doi.org/10.1021/bm025533+.

Veerman, C., Sagis, L. M. C., \& van der Linden, E. (2003). Gels at extremely low weight fractions $(0.07 \%)$ formed by irreversible self-assembly of proteins. Macromolecular Bioscience, 3(5), 243-247.

https://doi.org/10.1002/mabi.200390035.

Vieira, M. N. N., Fomy-Germano, L., Saraiva, L. M., Sebollela, A., Martinez, A. M. B., Houzel, J. C., . . F Ferreira, S. T. (2007). Soluble oligomers from a non-disease related protein mimic A beta-induced tau hyperphosphorylation and neurodegeneration. Journal of Neurochemistry, 103(2), 736-748. https://doi.org/10.1111/j.1471-4159.2007.04809.x.

Wang, J. M., Yang, X. Q., Yin, S. W., Yuan, D. B., Xia, N., \& Qi, J. R. (2011). Growth kinetics of amyloid-like fibrils derived from individual subunits of soy beta-conglycinin. Journal of Agricultural and Food Chemistry, 59(20), 11270-11277. https://doi.org/10.1021/jf202541m.

Wang, S. S. S., Chen, P. H., \& Hung, Y. T. (2006). Effects of p-benzoquinone and melatonin on amyloid fibrillogenesis of hen egg-white lysozyme. Journal of Molecular Catalysis B-Enzymatic, 43(1-4), 49-57. https://doi.org/10.1016/j.molcatb.2006.06.006.

Wang, S. S. S., Chou, S. W., Liu, K. N., \& Wu, C. H. (2009). Effects of glutathione on amyloid fibrillation of hen egg-white lysozyme. International Journal of Biological Macromolecules, 45(4), 321-329.

https://doi.org/10.1016/j.ijbiomac.2009.08.003.

Wang, S. S. S., Liu, K. N., Wu, C. H., \& Lai, J. K. (2009). Investigating the influences of redox buffer compositions on the amyloid fibrillogenesis of hen egg-white lysozyme. Biochimica et Biophysica Acta-Proteins and Proteomics, 1794(11), 1663-1672. https://doi.org/10.1016/j.bbapap.2009.07.017.

Watt, B., van Niel, G., Raposo, G., \& Marks, M. S. (2013). PMEL: A

pigment cell-specific model for functional amyloid formation. Pigment Cell E Melanoma Research, 26(3), 300-315.

https://doi.org/10.1111/pcmr.12067.

Weijers, M., Broersen, K., Barneveld, P. A., Stuart, M. A. C., Hamer, R. J., De Jongh, H. J., \& Visschers, R. W. (2008). Net charge affects morphology and visual properties of ovalbumin aggregates. Biomacromolecules, 9(11),

3165-3172. https://doi.org/10.1021/Bm800751e.

Weijers, M., Sagis, L. M. C., Veerman, C., Sperber, B., \& van der Linden, E. (2002). Rheology and structure of ovalbumin gels at low $\mathrm{pH}$ and low ionic strength. Food Hydrocolloids, 16(3), 269-276.

https://doi.org/10.1016/S0268-005x(01)00097-2.

Weijers, M., Visschers, R. W., \& Nicolai, T. (2004). Influence of the ionic strength on the structure of heat-set globular protein gels at $\mathrm{pH} 7$.

Ovalbumin. Macromolecules, 37(23), 8709-8714.

https://doi.org/10.1021/Ma048918o.

Wu, X. L., Nishinari, K., Gao, Z. M., Zhao, M., Zhang, K., Fang, Y. P., .. Jiang, F. T. (2016). Gelation of beta-lactoglobulin and its fibrils in the presence of transglutaminase. Food Hydrocolloids, 52, 942-951. https://doi.org/10.1016/j.foodhyd.2015.09.012.

Xue, W. F., Hellewell, A. L., Gosal, W. S., Homans, S. W., Hewitt, E. W., \& Radford, S. E. (2009). Fibril fragmentation enhances amyloid cytotoxicity. Journal of Biological Chemistry, 284(49), 34272-34282.

https://doi.org/10.1074/jbc.M109.049809. 